\title{
Determination of Corrosion Inhibitor Criteria for Type III/IIIA Tanks During Salt Dissolution Operations
}

\author{
B. J. Wiersma \\ J. I. Mickalonis \\ Savannah River National Laboratory \\ Materials Science and Technology
}

September 2007

\section{Washington Savannah River Company Savannah River Site Aiken, SC 29808}

This document was prepared in connection with work done under Contract No. DE-AC0996SR18500 with the U. S. Department of Energy 


\section{DISCLAIMER}

This report was prepared as an account of work sponsored by an agency of the United States Government. Neither the United States Government nor any agency thereof, nor any of their employees, makes any warranty, express or implied, or assumes any legal liability or responsibility for the accuracy, completeness, or usefulness of any information, apparatus, product, or process disclosed, or represents that its use would not infringe privately owned rights. Reference herein to any specific commercial product, process, or service by trade name, trademark, manufacturer, or otherwise does not necessarily constitute or imply its endorsement, recommendation, or favoring by the United States Government or any agency thereof. The views and opinions of authors expressed herein do not necessarily state or reflect those of the United States Government or any agency thereof. 
WSRC-STI-2006-00029

September 2007

Revision 0

DOCUMENT: $\quad$ WSRC-STI-2006-00029

TITLE: Determination of Corrosion Inhibitor Criteria for Type III/IIIA Tanks During Salt Dissolution Operations

APPROVALS:

Date:

B. J. Wiersma, Author

Materials Performance and Corrosion Technology

Materials Science and Technology

Date:

J. I. Mickalonis, Author

Materials Performance and Corrosion Technology

Materials Science and Technology

Date:

P. E. Zapp, Technical Reviewer

Materials Performance and Corrosion Technology

Materials Science and Technology

Date:

G. T. Chandler, Manager

Materials Performance and Corrosion Technology

Materials Science and Technology

Date:

N. C. Iyer, Director

Materials Science and Technology
K. S. Parkinson, Lead

Liquid Waste Process Engineering

Date:

Date:

C. M. Cole, Technical Reviewer Liquid Waste Process Engineering

Date:

D. J. Martin, Lead

Liquid Waste Process Engineering 
Revision 0

\section{Table of Contents}

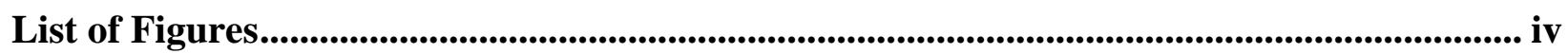

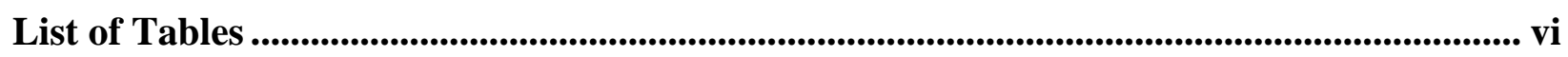

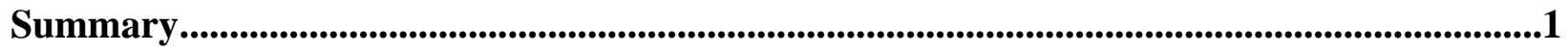

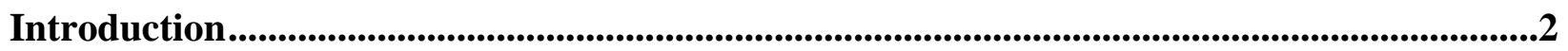

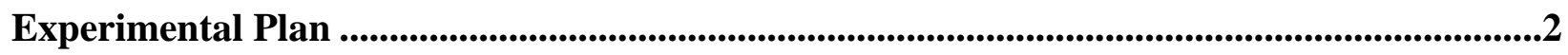

First Phase Testing......................................................................................................................2

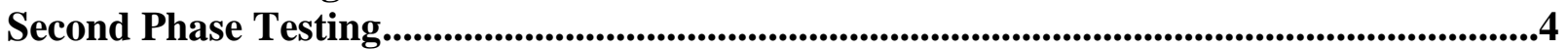

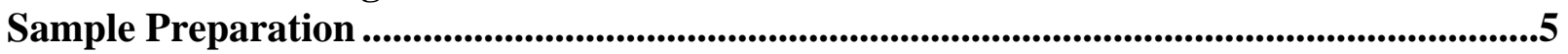

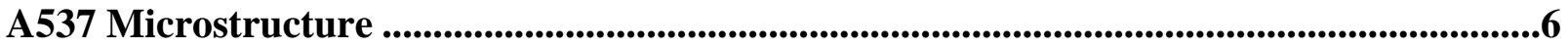

Background on Interpretation of Electrochemical Testing Results......................................9

Cyclic Potentiodynamic Polarization ..........................................................................................99

Open Circuit Potential Measurements......................................................................................12

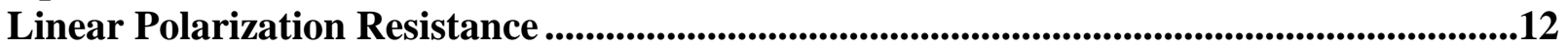

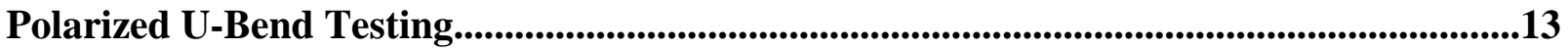

Results and Discussion..........................................................................................................14

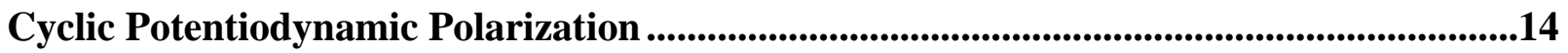

Pitting Data......................................................................................................................................19

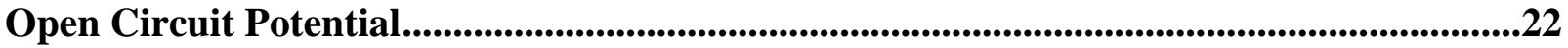

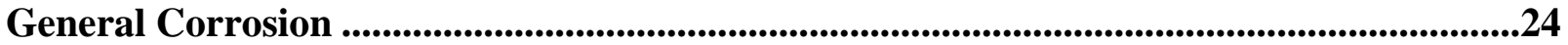

Polarized U-bend Testing .....................................................................................................25

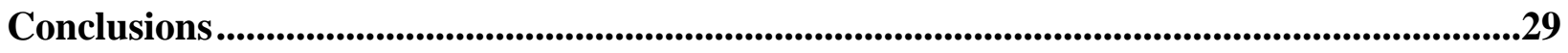

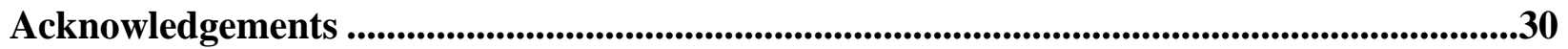

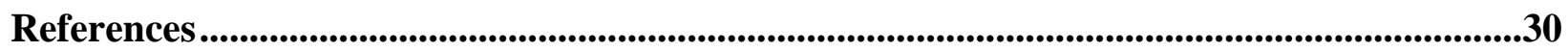




\section{LIST OF FIGURES}

Figure 1. Test Set Up For Second Phase Testing With Stressed Polarized U-bends;

(A) Prepared Unstressed U-bend, (B) Test Bottles In Oven

Figure 2. Microstructure of Rolled A537 Carbon Steel Plate Used For Making Ubends: (A) top of plate, (B) parallel to rolling direction, (C) perpendicular to rolling direction

Figure 3. Microstructures near edge of plate, top view; (A) bainite, (B) recrystallized ferrite.

Figure 4. Microstructure of Welded Ubend Sample ..................................................... 8

Figure 5. Plot of schematic CPP data showing characteristic potentials and currents ......9

Figure 6. Plots of CPP curves performed on freshly polished samples.............................11

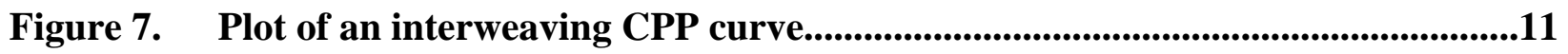

Figure 8. Typical Linear Polarization Curve For High Nitrate Solutions...........................12

Figure 9. Current-Time Traces At Applied Potential of 0.0V, Ag/AgCl For A537 U-Bend Exposed to 7M Sodium Nitrate Solution at $95{ }^{\circ} \mathrm{C}$..............................................13

Figure 10. Plot showing the relationship between the Eb and the Ecorr at the medium

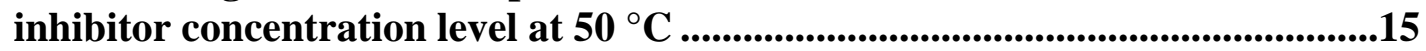

Figure 11. Plot demonstrating that Ecorr is independent of temperature .........................17

Figure 12. Plot demonstrating that Ecorr is independent of inhibitor concentration .........17

Figure 13. Relationship between Ecorr, Eb, and Erp for polished samples at $50{ }^{\circ} \mathrm{C} \ldots . . . . . .20$

Figure 14. Relationship between Ecorr, Eb, and Erp for polished samples at $25{ }^{\circ} \mathrm{C} \mathrm{.........20}$

Figure 15. Relationship between Ecorr, Eb, and Erp for exposed samples at $50{ }^{\circ} \mathrm{C}$ for low (0.01 M OH), medium (0.1 M OH) and high (0.6 M OH) inhibitor levels .........21

Figure 16. Relationship between Ecorr, Eb, and Erp for exposed samples at $25{ }^{\circ} \mathrm{C}$ for low (0.01 M OH), medium (0.1 M OH) and high (0.6 M OH) inhibitor levels .........22

Figure 17. Photographs of pitting and crevice attack that occurred during the CPP scan in solutions of $5.5 \mathrm{M}$ nitrate at $50 \mathrm{C}$ with (A) low inhibitor and (B) medium inhibitor concentrations 
Figure 18. Plot of OCP data for 5.5 M nitrate solution, low inhibitor concentration at 25 ${ }^{\circ} \mathrm{C}$. The gap indicates where data was not collected for approximately $\mathbf{3 0}$ hours.

Figure 19. Photographs of the As-received (A) and Heat-treated (B) U-bend After Testing

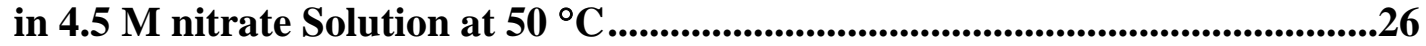

Figure 20. Photographs of U-bend After Testing in $4.5 \mathrm{M}$ Nitrate Solution ........................26

Figure 21. Current Scans For Cracking in As-Received U-bends at 50 C...........................28

Figure 22. U-bend exposed to $7 \mathrm{M}$ nitrate, $0.3 \mathrm{M}$ hydroxide and $0.2 \mathrm{M}$ nitrite after testing (A) and cleaned (B) of corrosion products.................................................................29 
Revision 0

\section{LIST OF TABLES}

Table 1. Experimental Test Conditions For First Phase .....................................................3

Table 2. Low Concentration Chemical Constituents Used In Test Solution ..........................4

Table 3. Inhibitor Concentrations For Third Series U-bend Testing .................................5

Table 4. Chemical Composition (Wt \%) of A537 Carbon Steel .............................................5

Table 5. Summarized CPP Data For Freshly Polished Samples at $50{ }^{\circ} \mathrm{C}$............................16

Table 6. Summarized CPP Data For Freshly Polished Samples at $25^{\circ} \mathrm{C}$.........................16

Table 7. Summary Data from CPP tests Performed on Previously Exposed Samples .......19

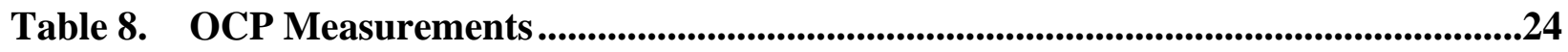

Table 9. General Corrosion Rates at the Stable Open Circuit Potentials ..........................25

Table 10. Current State During Polarized U-bend Testing at $50{ }^{\circ} \mathrm{C}$...................................27 


\section{Summary}

Preparation of high level waste for vitrification involves in part the dissolution of salt cake from the carbon steel storage tanks. The salt crystals composing this cake are high in nitrate concentration with the interstitial liquid being high in hydroxide and nitrite concentration. During the salt dissolution process, a stage is reached in which the inhibitors, hydroxide and nitrite, are insufficient to prevent nitrate stress corrosion cracking (SCC) and fall outside the requirements of the corrosion control program. Additional inhibitors, which are necessary to meet the requirements, may be counterproductive to the efficiency of the process and waste minimization.

Corrosion testing was initiated to better characterize the necessary inhibitor concentration for high nitrate waste during salt dissolution processing. A four-phase test program is being conducted: 1) electrochemical characterization, 2) accelerated or polarized U-bend testing, 3) long-term (non-polarized) U-bend testing and 4) vapor space U-bend tests. Electrochemical testing, which included cyclic potentiodynamic polarization (CPP), linear polarization resistance (LPR) and open-circuit potential (OCP) measurements, was performed to identify stress corrosion cracking susceptibility, to characterize pitting resistance and to determine the general corrosion rate. Polarized U-bend tests were utilized to assess the effect of minimum inhibitor concentrations and heat treatment on SCC and to determine test parameters for future long-term U-bend testing.

Results from CPP, LPR and OCP tests demonstrated that carbon steel formed a protective oxide film and the potential became electropositive during exposure to the waste at all inhibitor concentrations. The tenacity of this film improved as the inhibitor concentration level was increased and the temperature was decreased. This passive film increased the resistance to localized corrosion significantly. Therefore if any of these inhibitor levels are selected for storage of dissolved salt solutions, no changes to the service life estimates that were based on general corrosion are necessary.

The breakdown potential for SCC as well as the other electrochemical parameters were independent of nitrate concentration (4.5-8.5 M). The breakdown potential, however, was strongly affected by temperature (i.e., 25 and $50{ }^{\circ} \mathrm{C}$ ) and inhibitor concentration. These results indicate that for this nitrate concentration range a critical inhibitor level is necessary for minimizing the occurrence of SCC.

The polarized U-bend tests were in good agreement with the electrochemical tests. The U-bend testing clearly demonstrated that the heat treating of the samples clearly improved the SCC resistance of A537 carbon steel even at the low inhibitor concentration (0.01 M hydroxide and $0.01 \mathrm{M}$ nitrite). This concentration was insufficient to prevent cracking for any tested nitrate concentration (4.5-8.5 M). At a $7 \mathrm{M}$ nitrate concentration, SCC was prevented for inhibitor concentrations as low as $0.3 \mathrm{M}$ hydroxide and $0.1 \mathrm{M}$ nitrite. The current inhibitor requirements for a waste containing $7 \mathrm{M}$ nitrate are $0.6 \mathrm{M}$ hydroxide and $1.1 \mathrm{M}$ hydroxide and nitrite. Thus, a considerable reduction in the amount of inhibitor necessary may be attained. It will also be recommended that the temperature of the dissolved salt solution be maintained below $50{ }^{\circ} \mathrm{C}$. 


\section{Introduction}

High-level waste is stored at SRS in large underground tanks constructed of carbon steel. As part of waste storage management, the fresh waste from the canyons is evaporated in order to reclaim tank space. The hot liquid from the evaporator is cooled in a waste tank and crystallizes forming a material referred to as salt cake. The salt crystals tend to be rich in nitrate, while the interstitial liquid in equilibrium with the crystals tends to contain more hydroxide and nitrite.

In order to prepare feed for the Defense Waste Processing Facility, the salt cake must be dissolved. Water is utilized to dissolve the salt cake so that it can be transferred to the feed preparation tank. Several processes have been utilized to perform this operation at SRS [1].

An administrative control program is in place to prevent the initiation of corrosion processes in the tank during salt dissolution operations [2]. Given the high nitrate concentrations in the salt cake, the primary corrosion mechanism of concern is nitrate stress corrosion cracking (SCC). During the salt dissolution process a stage is achieved in which the inhibitor concentrations may not meet the requirements of the corrosion control program. This occurrence has been demonstrated in laboratory experiments [1], material balance models [3], and from in-tank waste samples [4]. Although the addition of inhibitors to the water utilized to dissolve the salt is necessary to meet the requirements, this action can be counterproductive to the efficiency of the process and to waste minimization.

The basis for the corrosion control limits for salt dissolution is being revisited with the desire to further investigate the risks associated with operating at these lower inhibitor concentrations for the short period of time that salt dissolution occurs (i.e., typically operational plans call for dissolution to be completed within 2 to 6 years). Laboratory testing was initiated as described in the initial test plan [5]. The test plan laid out a program consisting of four test phases: 1) cyclic polarization (CP) and electrochemical characterization, 2) accelerated or polarized U-bend testing, 3) long-term (non-polarized) U-bend testing and 4) vapor space U-bend tests. This document presents results on the electrochemical and polarized U-bend testing that has been completed to date.

\section{Experimental Plan}

\section{First Phase Testing}

The first phase consisted of three electrochemical tests to characterize the corrosion of carbon steel in high nitrate solutions. Specifically, these tests were open-circuit potential measurements (OCP), linear polarization resistance (LPR), and cyclic potentiodynamic polarization (CPP). For each test condition in the first phase, four samples were used. Two samples were exposed to the solution at temperature for one week. During this time OCP and LPR were conducted periodically. At the end of a week, the samples were tested using CPP. The remaining two samples were tested by CPP under test conditions immediately after being prepared. The prompt testing with clean pristine surfaces is expected to provide a more conservative corrosion assessment. 
The weekly exposures were performed in wide-mouth polyethylene bottles with approximately $500 \mathrm{ml}$ of solution. For electrochemical testing, a test cell consists of three electrodes, the working, counter and reference electrodes. Graphite carbon electrodes were used as counter electrodes and a Ag/AgCl reference electrode was used for potential measurement. All potentials in this report are given with respect to this reference electrode. The working electrode is the sample or material of interest, which in this case is A537 carbon steel. Details of the working electrode are described below. The bottles were placed into an oven for the elevated temperature testing. The CPP tests were conducted in glass vessels with fresh solution. After testing samples were evaluated and photographed.

Eleven different test solutions were used during the first phase consisting of a wide range of nitrate concentrations (4.5 to $8.5 \mathrm{M}$ ). Three discrete inhibitor (nitrite and hydroxide) concentrations were used and testing was conducted at two different temperatures, 25 and $50{ }^{\circ} \mathrm{C}$. The experimental test matrix consisted of nineteen conditions as shown in Table 1.

Table 1. Experimental Test Conditions For First Phase

\begin{tabular}{|c|c|c|c|c|c|}
\hline \multirow{2}{*}{ Test \# } & Solution \# & Temperature & \multicolumn{3}{|c|}{ General Solution Chemistries } \\
\cline { 4 - 6 } & & $(\mathbf{C})$ & Nitrate (M) & Nitrite (M) & Hydroxide (M) \\
\hline 1 & 1 & 25 & 5.5 & 0.01 & 0.01 \\
\hline 2 & 2 & 25 & 5.5 & 0.1 & 0.1 \\
\hline 3 & 3 & 25 & 5.5 & 0.2 & 0.6 \\
\hline 4 & 4 & 25 & 7.0 & 0.01 & 0.01 \\
\hline 5 & 5 & 25 & 7.0 & 0.1 & 0.1 \\
\hline 6 & 6 & 25 & 7.0 & 0.2 & 0.6 \\
\hline 7 & 1 & 50 & 5.5 & 0.01 & 0.01 \\
\hline 8 & 2 & 50 & 5.5 & 0.1 & 0.1 \\
\hline 9 & 3 & 50 & 5.5 & 0.2 & 0.6 \\
\hline 10 & 4 & 50 & 7.0 & 0.01 & 0.01 \\
\hline 11 & 5 & 50 & 7.0 & 0.1 & 0.1 \\
\hline 12 & 6 & 50 & 7.0 & 0.2 & 0.6 \\
\hline 13 & 7 & 50 & 8.5 & 0.01 & 0.01 \\
\hline 14 & 8 & 50 & 8.5 & 0.1 & 0.1 \\
\hline 15 & 9 & 50 & 8.5 & 0.2 & 0.6 \\
\hline 16 & 10 & 25 & 4.5 & 0.01 & 0.01 \\
\hline 17 & 11 & 25 & 4.5 & 0.1 & 0.1 \\
\hline 18 & 10 & 50 & 4.5 & 0.01 & 0.01 \\
\hline 19 & 11 & 50 & 4.5 & 0.1 & 0.1 \\
\hline
\end{tabular}

The solutions also had additional constituents that were constant for all solutions. These constituent and the molar concentrations are shown in Table 2. 
Table 2. Low Concentration Chemical Constituents Used In Test Solution

\begin{tabular}{|c|c|}
\hline Chemical & $\begin{array}{c}\text { Concentration } \\
\text { (M) }\end{array}$ \\
\hline $\mathrm{NaAlO}_{2}$ & 0.5 \\
\hline $\mathrm{Na}_{2} \mathrm{CO}_{3}$ & 0.1 \\
\hline $\mathrm{Na}_{2} \mathrm{SO}_{4}$ & 0.1 \\
\hline $\mathrm{Na}_{2} \mathrm{HPO}_{4} \times 7 \mathrm{H}_{2} \mathrm{O}$ & 0.05 \\
\hline $\mathrm{NaCl}$ & 0.1 \\
\hline
\end{tabular}

CPP and LPR are accelerated tests by the application of an applied potential. OCP is conducted by monitoring the equilibrium or open-circuit potential of a sample against that of a reference over a period of time. For LPR, a potential is applied over a small range, $30 \mathrm{mV}$, around the open-circuit potential. The scan rate typically was $0.5 \mathrm{mV} / \mathrm{sec}$. The responding current is recorded and a resistance is calculated from the resultant potential/current relationship. This resistance is proportional to the corrosion current or rate as discussed in the next section. CPP testing is performed by polarizing a sample with a ramp function from its open-circuit potential to a vertex potential. At the vertex potential the scan is reversed with a potential ramp in the reverse direction. The scan rate was $0.5 \mathrm{mV} / \mathrm{sec}$ and the vertex potential was generally $1 \mathrm{~V}$ more electropositive than the open-circuit potential. Interpretations of the electrochemical test data are discussed in the next section.

For both the first and second phase, the electrochemical instrumentation was computercontrolled Ametek PAR 273A and Gamry PCI4/750 potentiostats. The polarized U-bend tests also used a Gamry multiplexer for continuous polarization of multiple samples.

\section{Second Phase Testing}

The second phase testing used potentiostatic polarization with an A537 U-bend. Potentiostatic polarization is conducted by applying a constant potential to the working electrode (U-bend) and monitoring the responding current. The potential is chosen to bring the sample into a possible range for SCC. The cell consisted of a Ag/AgCl reference electrode, a 304L stainless steel mesh counter electrode, and a stressed polarized U-bend. Description of the U-bend is given below. A wide-mouth polyethylene bottle was the test vessel and contained approximately $500 \mathrm{ml}$ of solution. The bottles were placed in an oven to obtain the test temperature of $50^{\circ} \mathrm{C}$. Evaporative losses from the solution were replaced by distilled water. Figure 1 shows an unstressed U-bend prior to testing and the set up of bottles in the oven.

Three series of tests were conducted. The first series consisted of several tests in which U-bends were polarized in $7 \mathrm{M}$ nitrate solutions with no additional constituents. Tests were performed at both 50 and $95{ }^{\circ} \mathrm{C}$. For the $95^{\circ} \mathrm{C}$ test, a U-bend was tested with and without a small slot. The slot was used as a stress raiser for crack initiation. For the second series, the U-bends were tested in four different nitrate solutions, $4.5,5.0,7.0$, and $8.5 \mathrm{M}$, all contained the same low inhibitor level of $0.01 \mathrm{M}$ hydroxide and $0.01 \mathrm{M}$ nitrite. The low concentration constituents shown in Table 2 were also added to the solutions. For each solution, two U-bends were tested, as-received and heat treated samples, as described below. 


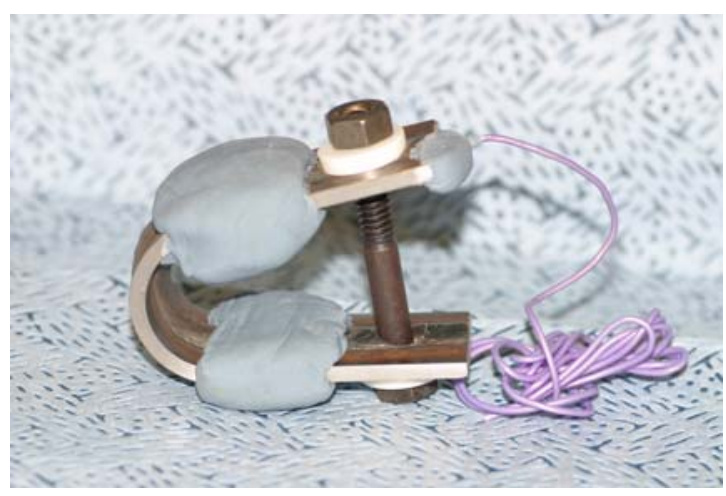

(A)

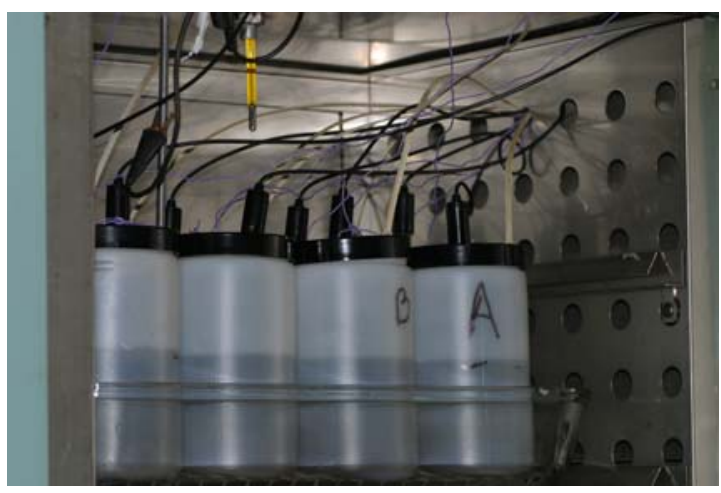

(B)

Figure 1. Test Set Up For Second Phase Testing With Stressed Polarized U-bends; (A) Prepared Unstressed U-bend, (B) Test Bottles In Oven

The third series testing was performed in $7 \mathrm{M}$ nitrate solutions over a wide range of inhibitor concentrations. The inhibitor concentrations are given in Table 3, which shows the nitrite concentrations for two hydroxide concentrations. The minor constituents as shown in Table 2 were also added. Testing was conducted at $50{ }^{\circ} \mathrm{C}$. The U-bends were polarized initially to $0.0 \mathrm{~V}$ versus $\mathrm{Ag} / \mathrm{AgCl}$. The polarization potential was stepped up to $0.1 \mathrm{~V}$ and then $0.2 \mathrm{~V}$ versus $\mathrm{Ag} / \mathrm{AgCl}$ if cracking did not occur. Also during this series, the low inhibitor condition (0.01 M nitrite and $0.01 \mathrm{M}$ hydroxide) for the 4.5 and 7.0 $\mathrm{M}$ nitrate solutions were repeated.

Table 3. Inhibitor Concentrations For Third Series U-bend Testing

\begin{tabular}{|c|c|}
\hline Hydroxide (M) & Nitrite (M) \\
\hline 0.6 & $0.01,0.2,0.3$ \\
\hline 0.3 & $0.01,0.1,0.2,0.3$ \\
\hline
\end{tabular}

Sample Preparation

Test samples were fabricated from A537 carbon steel, class 1, which is a low carbon normalized steel. Normalizing the steel refines the grain size for subsequent processing. All specimens were made from the same heat and plate of material. The composition of the material is shown in Table 4 with the balance being Fe [6].

Table 4. Chemical Composition (Wt \%) of A537 Carbon Steel

\begin{tabular}{|c|c|c|c|c|c|c|c|}
\hline $\mathbf{C}$ & $\mathbf{M n}$ & $\mathbf{P}$ & $\mathbf{S}$ & $\mathbf{C u}$ & $\mathbf{N i}$ & $\mathbf{C r}$ & $\mathbf{S i}$ \\
\hline 0.14 & 1.44 & 0.008 & 0.003 & 0.14 & 0.11 & 0.09 & 0.29 \\
\hline
\end{tabular}

For the first phase of testing, disks of material were taken from the same plate used to fabricate the U-bends. The disks were 0.75 in diameter. For each sample, a wire was attached to a side 
with a conductive silver epoxy. The sample was placed into a metallurgical mount. Prior to testing, the sample was ground to a 600-grit surface finish, rinsed and blown dry.

Prior to fabrication of the U-bends, the plates were butt welded transverse to the rolling direction of the plate using a shielded metal arc procedure with E7018 H4R welding electrodes. Coupons were then laser cut from the plate with the weld in the long transverse-longitudinal orientation and centered with respect to the transverse direction or width; coupon size was 5 in long, 1.5 in wide and 0.375 in thick. Samples were configured in this orientation so crack propagation would occur in the longitudinal rolling direction. Only the edges were ground to remove any burrs. The coupons were bent around a mandrel with radius of 0.505 in. The U-bends were received with mill oxide layers on both inside and outside surfaces. Each sample was stenciled with a unique number and the material grade. U-bends were made following G30-97, "Making and Using U-bend Stress-Corrosion Test Specimens”.

The U-bend was prepared by attaching a wire to the top of an arm using silver epoxy and covering this location with a mounting epoxy. Prior to mounting, this surface was ground to a 600-grit surface finish. The location of the liquid/vapor interface on the U-bend was also covered with mounting epoxy to prevent corrosion at this location. The U-bend was stressed by a bolt placed through each arm near the top and tightened until the arms were parallel. The calculated strain on the bottom outer surface was approximately $13 \%$ ensuring that the applied stress was at the yield stress.

A heat treatment was performed on some samples to simulate the stress relief given to the Type III/IIIA waste tanks. Specifically, the heat treatment involved heating from ambient to $1100^{\circ} \mathrm{F}$ at a rate of $90{ }^{\circ} \mathrm{F} /$ hour, followed by a hold at $1100{ }^{\circ} \mathrm{F}$ for 60 minutes, and a cooling rate of 115 ${ }^{\circ} \mathrm{F} / \mathrm{hr}$ to ambient. The heat treatment was performed in air. No special surface preparations were performed prior to testing.

\section{A537 Microstructure}

The microstructure of the A537 carbon steel plate used to make the welded U-bend samples was investigated. Preparation of the sample for metallurgical analysis involved placing the sample in an epoxy mount, grinding and polishing the sample surface with increasingly finer SiC papers, and etching the prepared surface with a nital etchant (nitric acid and ethanol). The plate was primarily composed of proeutectoid ferrite and pearlite. Figure 2 shows the microstructures of the plate top, parallel to the rolling direction and perpendicular to the rolling direction. Banding has occurred as seen in the parallel microstructures, which is typical of rolled plates.

Several areas of bainite, possibly martensite, and recrystallized ferrite were found along edges of all the directional views. Both the top and perpendicular views showed bands consisting of both the bainite and recrystallized ferrite as shown in Figure 3 for the top view. The formation of bainite or martenite is dependent on the steel composition, cold working, and cooling from austentinizing temperatures. For A537, these crystal structures are not typical, but may be present because of the high manganese concentrations $(1.44 \%)$ in the material, which also affects transformation temperatures. Heating and cooling during cutting of the plate may have lead to these complex microstructures. 


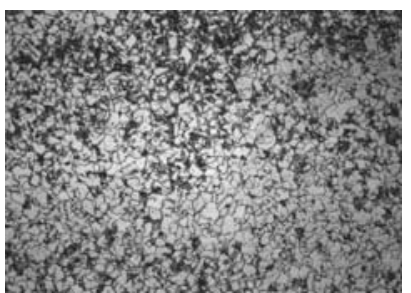

(A)

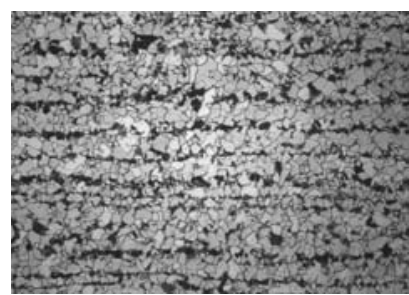

(B)

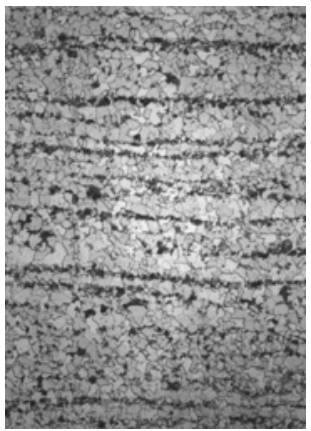

(C)

Figure 2. Microstructure of Rolled A537 Carbon Steel Plate Used For Making Ubends: (A) top of plate, (B) parallel to rolling direction, (C) perpendicular to rolling direction

A cross section of a welded U-bend was also examined. The section was taken from an upper arm of the U-bend away from the stressed region at the bottom of the U-bend. The microstructure was more complex as shown by the photomicrographs in Figure 4. The weld metal was composed of ferritic dendrites with interstices filled with pearlite. The heat affected zone (HAZ) appears to be composed of two bands. The band closest to the weld was composed of martensite and the outer band was recrystallized ferrite and pearlite. Farther from the weld the plate had the typical banded microstructure of ferrite and pearlite. Near the edge of the plate, the edge had a thick oxide layer.

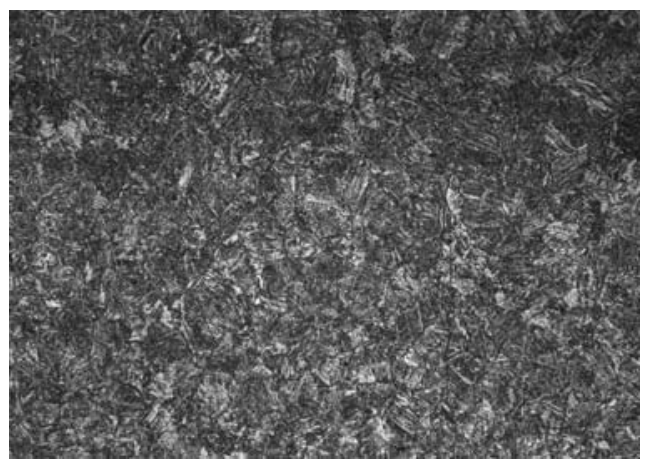

(A)

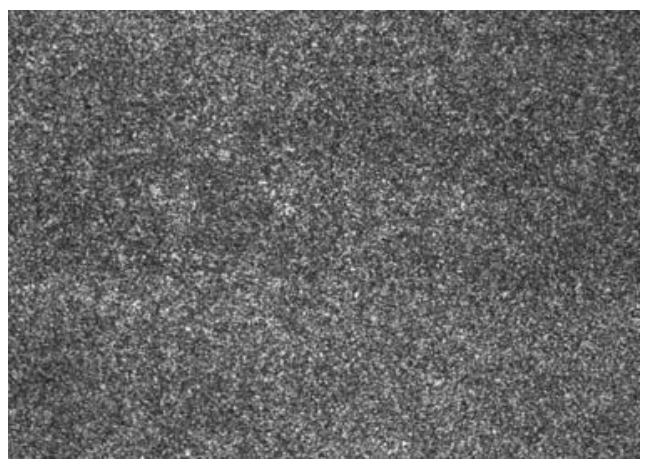

(B)

Figure 3. Microstructures near edge of plate, top view; (A) bainite, (B) recrystallized ferrite 


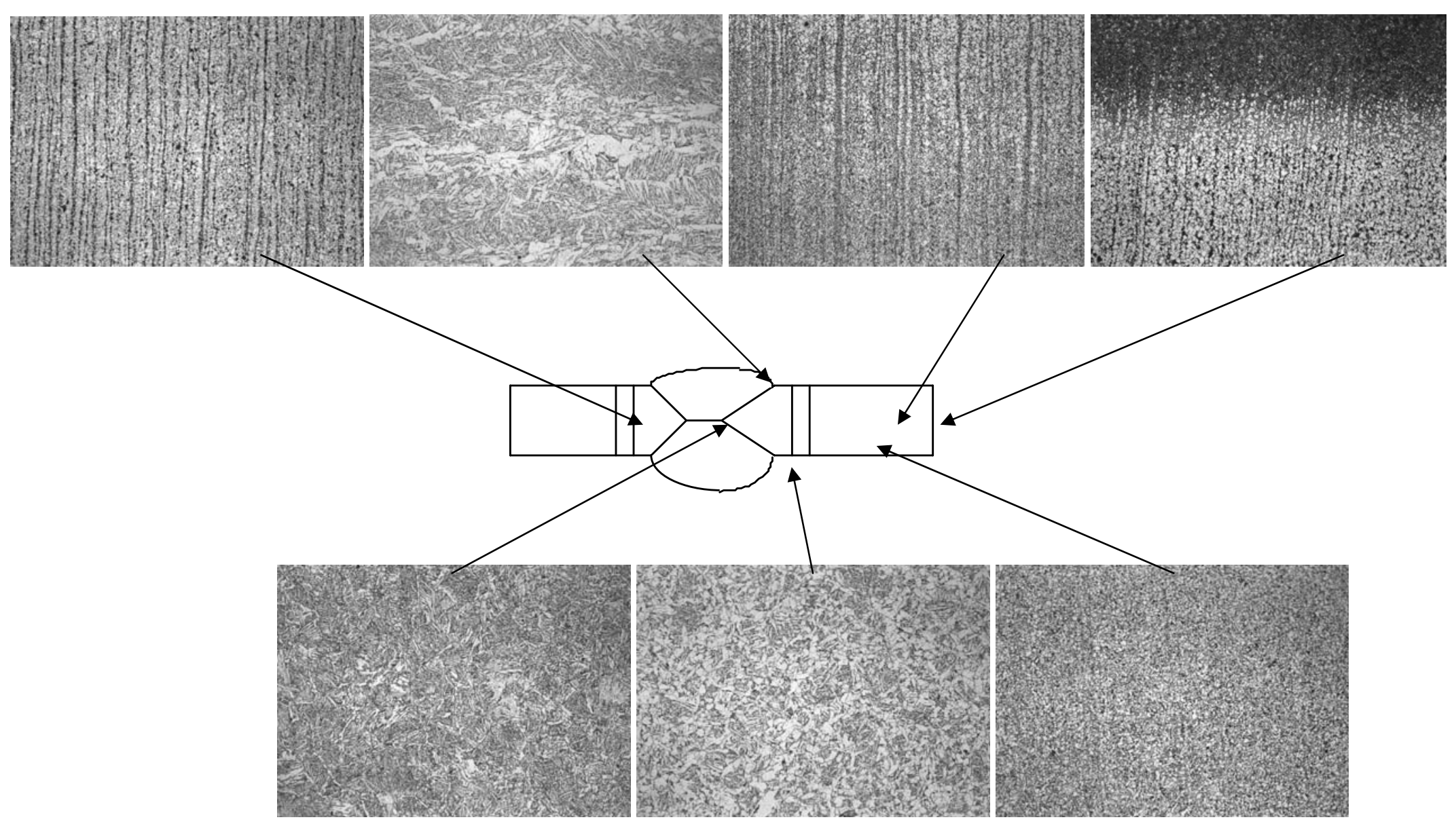

Figure 4. Microstructure of Welded Ubend Sample. 


\section{Background on Interpretation of Electrochemical Testing Results}

As discussed above, three electrochemical tests, CPP, OCP, and LPR, were utilized to investigate the corrosion mechanisms that are operative in dissolved salt solution environments. A brief description of the key parameters from each test and their interpretation is presented.

\section{Cyclic Potentiodynamic Polarization}

Cyclic potentiodynamic polarization is utilized to investigate the susceptibility of a material to localized corrosion in a given environment. A sample is exposed to the solution of interest and allowed to reach equilibrium. This test is initiated at the OCP. A sequentially increasing potential is then applied to the sample. The current response to the change in potential is measured to establish a current-potential relationship. An example of this relationship is shown in Figure 5. The corrosion potential, $\mathrm{E}_{\text {corr }}$, is the potential at which the net current flowing to or from the metal surface is zero, i.e., the anodic and cathodic currents are the same.

Various current responses that occur during the forward scan have been shown to be indicative of SCC behavior. In particular, the breakdown potential, $\mathrm{E}_{\mathrm{b}}$, is the potential where the current increases rapidly with a small change in potential. This change has been correlated with a reduction in the passive nature of the material. The passive to active transition region shown in Figure 5 is the region in which the material is susceptible to SCC. The smaller the difference between values of $E_{\text {corr }}$ and $E_{b}$, the more susceptible the material is to SCC in that environment.

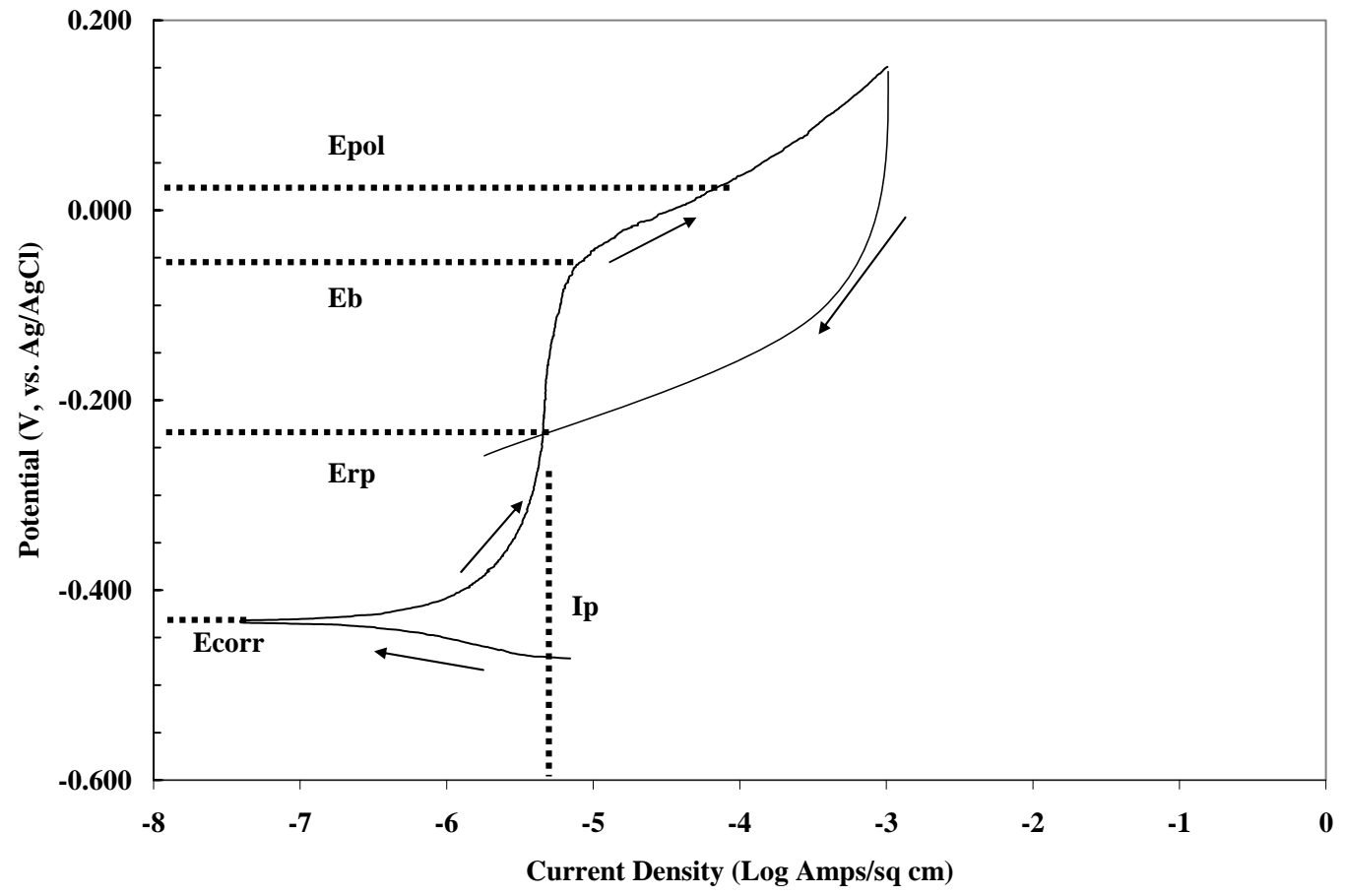

Figure 5. Plot of schematic CPP data showing characteristic potentials and currents 
Electrochemical control of stressed samples has been utilized to predict the SCC susceptibility of a material in a given environment. Examples of these types of tests are slow strain rate [7] and U-bend [8]. Frequently in tests performed at the OCP (i.e., potential is not perturbed) it has been observed that SCC does not occur, while in tests in the same environment in which the potential is controlled to a value in the cracking range SCC does occur [9]. Polarized U-bend tests in the second phase of testing were used to establish, in part, the threshold inhibitor requirements that will prevent the initiation of SCC. The applied potential for the U-bends is shown in Figure 5 as $\mathrm{E}_{\mathrm{pol}}$.

The cyclic polarization behavior also provides information on the susceptibility of the material to pit initiation and the likelihood of stable pit growth. Data from the reverse scan as well as the forward scan are utilized for this purpose. The additional parameters that were evaluated included the repassivation potential, $\mathrm{E}_{\mathrm{rp}}$, the observation of positive or negative hysterisis on the reverse scan, and the passive current density, $\mathrm{I}_{\mathrm{p}}$. The following guidelines were utilized to examine the CPP scans [10]:

- The differences of $E_{b}$ and $E_{r p}$ with $E_{c o r r}$ are a measure of the susceptibility of a material to a given environment. When comparing a materials behavior in different environments, a larger difference indicates greater resistance to localized corrosion.

- If $\mathrm{E}_{\mathrm{rp}}$ is more negative than $\mathrm{E}_{\mathrm{corr}}$, or if $\mathrm{E}_{\mathrm{rp}}$ is less than $200 \mathrm{mV}$ more positive than $\mathrm{E}_{\mathrm{corr}}$, the material is susceptible to crevice corrosion in the environment. This guideline makes allowances for variability in the measurement of these potentials.

- If the current density of the reverse scan is greater than that for the forward scan, localized corrosion is likely. This is known as negative hysterisis (see Figure 6, $7 \mathrm{M}$ nitrate, low inhibitor case).

- If the current density of the reverse scan is less than that for the forward scan, passive behavior is expected. This is known as positive hysterisis (see Figure 6, $8.5 \mathrm{M}$ nitrate, high inhibitor case).

- Occasionally the current density of the reverse scan is initially less than that of the forward scan however, as the scan proceeds towards $E_{\text {corr }}$, the reverse scan current density becomes greater than that for the forward scan creating an interweaving pattern (see Figure 7). If the cross-over potential $\left(\mathrm{E}_{\mathrm{co}}\right)$, the potential where the reverse and forward current density are equal, is more positive than $\mathrm{E}_{\mathrm{b}}$, the material is susceptible to localized corrosion. This behavior is indicative of the formation of an oxide film that is not protective. On the other hand if the cross-over occurs at or slightly less than the $\mathrm{E}_{\mathrm{b}}$, little or no localized corrosion is observed. In this case the increase in current at $\mathrm{E}_{\mathrm{b}}$ is not the result of breakdown in the oxide film, but rather what is referred to as transpassive behavior (i.e., reactions such as oxygen evolution are occurring). This potential is more commonly referred to as the transpassive potential, $\mathrm{E}_{\mathrm{t}}$. 
WSRC-STI-2006-00029

September 2007

Revision 0

Page 11 of 31

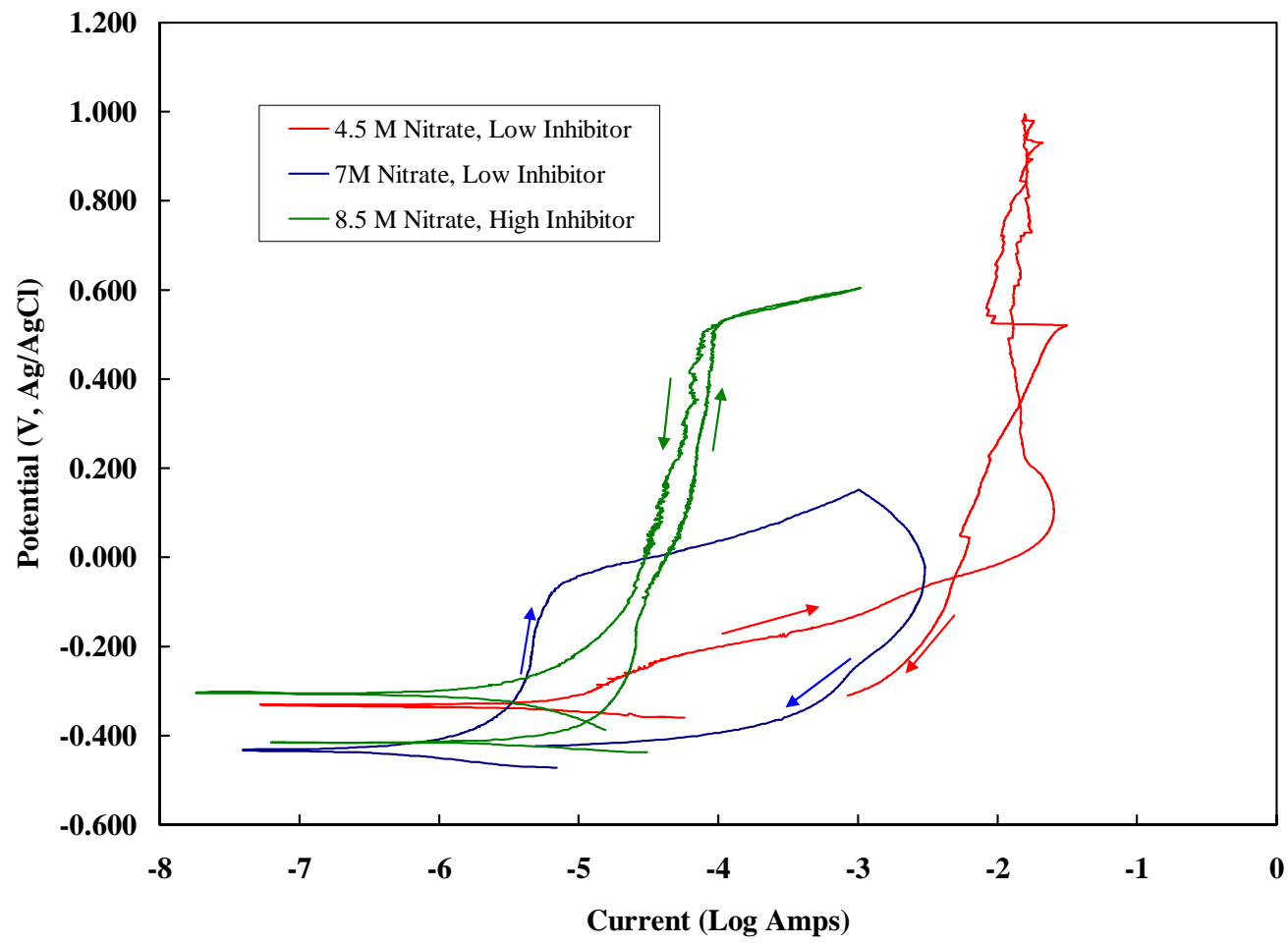

Figure 6. Plots of CPP curves performed on freshly polished samples.

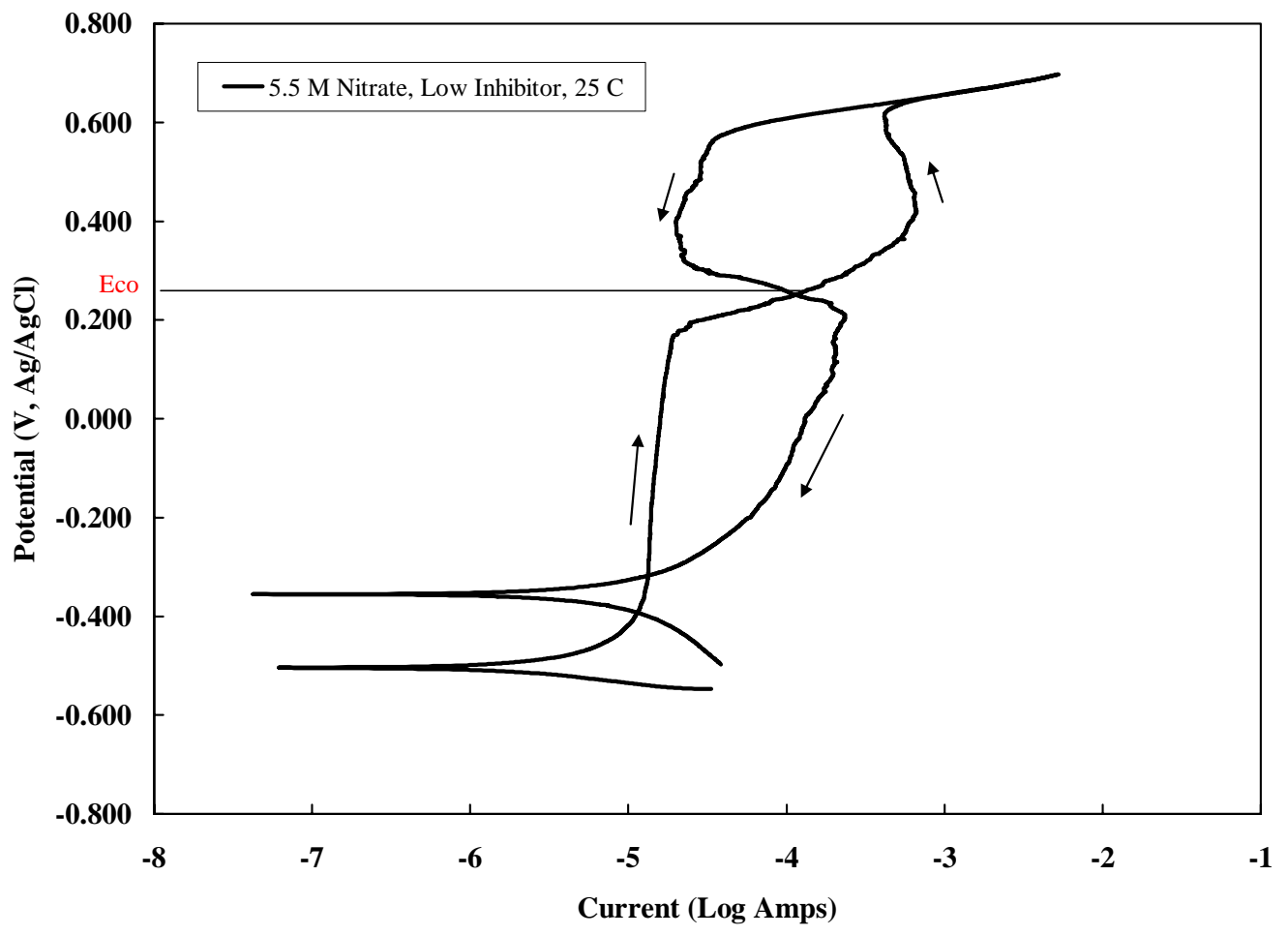

Figure 7. Plot of an interweaving CPP curve 


\section{Open Circuit Potential Measurements}

The OCP is the potential of a corroding surface in an electrolyte with respect to a reference electrode. The OCP is monitored over time and indicates any changes in the corrosion behavior of the material resulting from the exposure to the environment. For example, if the OCP were to shift so that it became more electropositive than $\mathrm{E}_{\mathrm{b}}$, the material would be susceptible to pitting corrosion. Likewise if the OCP were to become more electropositive than the repassivation potential the material would be susceptible to crevice corrosion. An increase in the OCP may also indicate that a protective oxide film is forming. The tests were also performed to determine the length of time necessary for the material to stabilize in the environment and to determine its location relative to the $\mathrm{E}_{\mathrm{b}}$ and $\mathrm{E}_{\mathrm{rp}}$.

\section{Linear Polarization Resistance}

The general corrosion rate of a material in a given environment is estimated from the polarization resistance, $R_{p}$, measured by this test [11]. The potential vs. current response is typically linear with a slope equal to $\mathrm{R}_{\mathrm{p}}$ (See Figure 8).

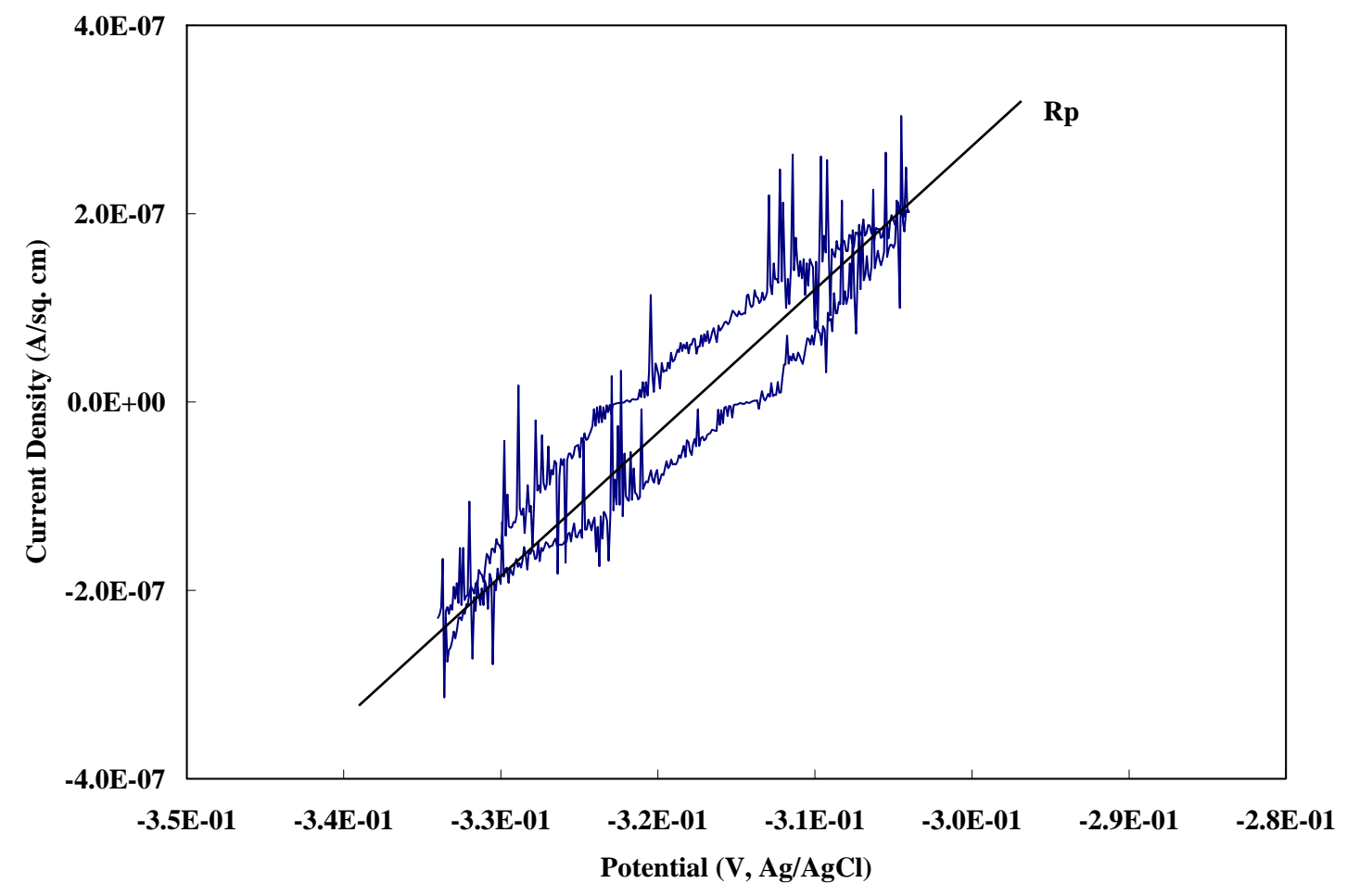

Figure 8. Typical Linear Polarization Curve For High Nitrate Solutions.

The general corrosion rate is then calculated using $R_{p}$ in the following equation:

$$
\mathrm{CR}=\frac{0.13 \mathrm{~b}_{\mathrm{a}} \mathrm{b}_{\mathrm{c}}(\mathrm{EW})}{2.3\left(\mathrm{~b}_{\mathrm{a}}+\mathrm{b}_{\mathrm{C}}\right) \mathrm{R}_{\mathrm{p}} \mathrm{d}}
$$


where CR is the corrosion rate in mils per year (mpy), $b_{a}$ and $b_{c}$ are the anodic and cathodic Tafel slopes, EW is the equivalent weight of the corroding species, and $\mathrm{d}$ is the density of the corroding species. For the calculations the Tafel slopes were assumed to be $100 \mathrm{mV} /$ decade (order of magnitude) of current, and the equivalent weight and density of iron are 27.5 g/equivalent and $7.8 \mathrm{~g} / \mathrm{cm}^{3}$, respectively. The advantage of this test is that it has a minimal effect on the surface.

Therefore, the test can be utilized as a non-destructive technique to monitor the general corrosion rate as a function of time. These tests were performed in conjunction with measurement of OCP to investigate changes in the general corrosion rate with an increase in the exposure time.

\section{Polarized U-bend Testing}

For polarized U-bends, the current is continuously monitored as a means to measure the corrosion process that is occurring on the sample at the applied potential. As discussed previously, this applied potential is chosen from the CPP curves for areas where SCC is believed to be more likely to occur. When a potential is initially applied, a large current is generated since the corrosion process is greatly accelerated. In this initial stage, general corrosion is accelerated with metal oxidation, and depending on the solution chemistry, corrosion products or adherent oxides are formed. As either the oxide or corrosion products build up, a resistance or barrier to current flow results and the current generally decreases to a low plateau valve as shown by the red curve in Figure 9 for the U-bend exposed to $7 \mathrm{M}$ nitrate solution with no inhibitors at $95{ }^{\circ} \mathrm{C}$.

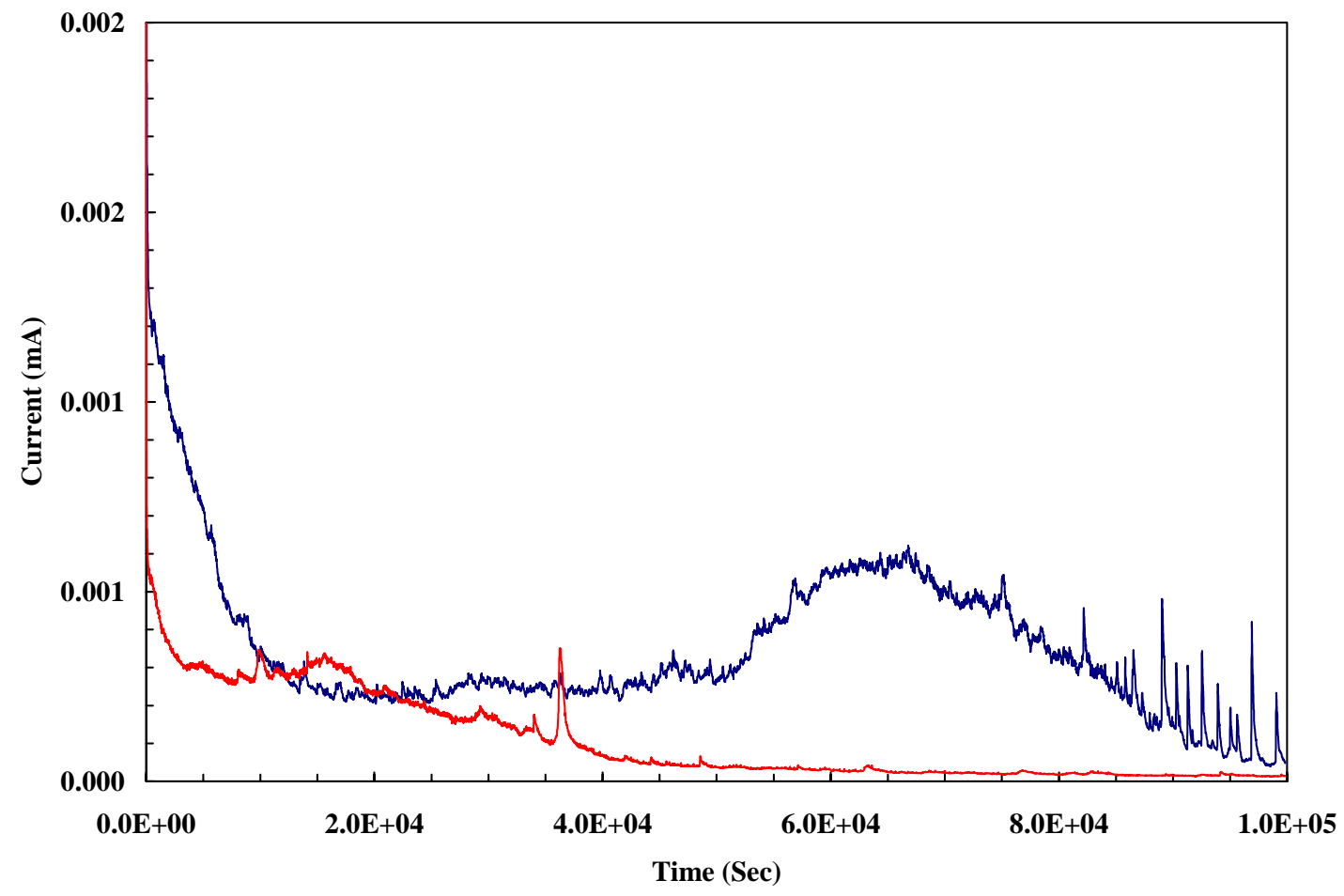

Figure 9. Current-Time Traces At Applied Potential of 0.0V, Ag/AgCl For A537 U-Bend Exposed to $7 \mathrm{M}$ Sodium Nitrate Solution at $95^{\circ} \mathrm{C}$. 
When a crack through the oxide film or precipitated compound exposes fresh metal (i.e. zerovalent), the current increases from the corrosion of this metal. As the crack proceeds, the current will increase until the area of fresh surface is maximized. Corrosion product formation and oxidation will slowly build a barrier to current flow leading to a drop in measured current. This current scan is shown by the blue curve in Figure 9 for the same conditions but at a later time.

These current-time scans in Figure 9 are relatively free of numerous current spikes, peaks and plateaus. Current scans can be noisy depending on the material, solution chemistry, and measuring equipment. The current scans in the more complex waste simulants had more noise in the data, which is primarily associated with the solution chemistry since the equipment and samples were nominally the same.

\section{Results and Discussion}

The results for the first and second phase are discussed separately. The first phase includes the results from the three electrochemical techniques, CPP, LPR and OCP. The second phase test results are those for the polarized U-bends.

\section{Cyclic Potentiodynamic Polarization}

The results from CPP scans performed on the samples that were polished were primarily utilized to establish $E_{\text {pol }}$ for the polarized U-bend tests. The $E_{b}$ measured during the forward scan is the most significant parameter in this determination. Figure 6 illustrates the three types of curves that were observed. The corrosion behavior demonstrated in the test at $7 \mathrm{M}$ nitrate with a low inhibitor concentration was observed most frequently. As shown in the figure, a clear passive regime and $E_{b}$ were seen, indicative of breakdown of the passive film. The corrosion behavior for the test at $4.5 \mathrm{M}$ nitrate with a low inhibitor concentration did not exhibit a clear passive regime and $\mathrm{E}_{\mathrm{b}}$ was close to $\mathrm{E}_{\text {corr }}$. This behavior is more indicative that aggressive general corrosion of the metal is occurring. One test performed at $8.5 \mathrm{M}$ nitrate with a high inhibitor concentration exhibited passive behavior for the entire region that was scanned. The increase in current density at a potential near $0.550 \mathrm{~V}$ indicates transpassive behavior where oxygen evolution occurs.

The effects of nitrate concentration, temperature and inhibitor concentration on $\mathrm{E}_{\mathrm{corr}}, \mathrm{E}_{\mathrm{b}}$, and $\mathrm{I}_{\mathrm{p}}$ were investigated. Within the range tested, these electrochemical parameters exhibited no dependence on the nitrate concentration. Figure 10 shows that for the medium inhibitor level at $50{ }^{\circ} \mathrm{C} \mathrm{E}_{\text {corr }}$ is consistently within a $150 \mathrm{mV}$ range irrespective of the inhibitor concentration or temperature (see Figures 11 and 12). The initial value for $\mathrm{E}_{\text {corr }}$ is primarily within the range of -300 to $-450 \mathrm{mV}$. The same conclusion may be drawn from Tables 5 and 6 . The average $\mathrm{E}_{\text {corr }}$ for all the data is approximately $-350 \mathrm{mV}$. 


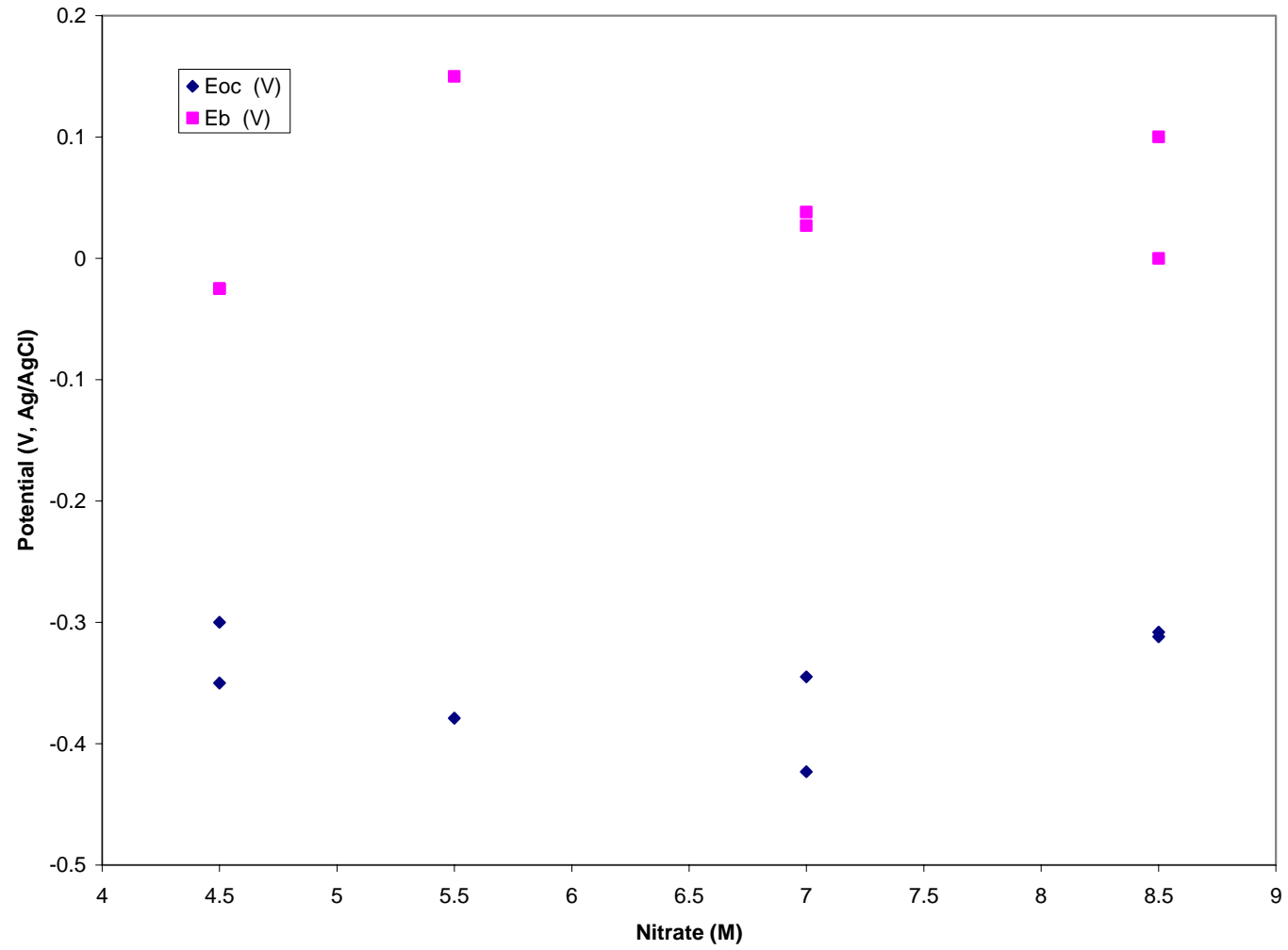

Figure 10. Plot showing the relationship between the $E_{b}$ and the $E_{c o r r}$ at the medium inhibitor concentration level at $50^{\circ} \mathrm{C}$

The $\mathrm{E}_{\mathrm{b}}$ at a constant inhibitor level and temperature was essentially independent of nitrate concentration and also typically within a $150 \mathrm{mV}$ range (see Figure 10). However, unlike Ecorr, $\mathrm{E}_{\mathrm{b}}$ did show a dependence on the inhibitor concentration and temperature. Table 5 shows that at $50{ }^{\circ} \mathrm{C}$, the $\mathrm{E}_{\mathrm{b}}$ increases approximately $100 \mathrm{mV}$ with each level of inhibitor concentration. Table 7 shows that at $25^{\circ} \mathrm{C}$ the increase in $\mathrm{E}_{\mathrm{b}}$ with inhibitor concentration level is less pronounced at approximately $50 \mathrm{mV}$ for each level of inhibitor concentration. However, the values for $\mathrm{E}_{\mathrm{b}}$ at the lower temperature were generally more positive than those at the higher temperature. For example, at $50{ }^{\circ} \mathrm{C}$, and the medium inhibitor level, the average $\mathrm{E}_{\mathrm{b}}$ is approximately $+38 \mathrm{mV}$, whereas at $25^{\circ} \mathrm{C}$ and the medium inhibitor level the average $\mathrm{E}_{\mathrm{b}}$ is $+86 \mathrm{mV}$. Higher inhibitor concentration levels and lower temperatures are expected to reduce the solution corrosion activity.

The $I_{p}$ also provides a measure of the aggressiveness of the environment. Tables 6 and 7 indicate that $I_{p}$ is not sensitive to the inhibitor levels tested, however, $I_{p}$ does depend on temperature. At a constant inhibitor level, the $\mathrm{I}_{\mathrm{p}}$ increases by a factor of 2 to 5 as the temperature is increased from 25 to $50{ }^{\circ} \mathrm{C}$. This behavior was also expected as higher temperatures tend to promote more aggressive corrosion activity. 
Table 5. Summarized CPP Data For Freshly Polished Samples at $50^{\circ} \mathrm{C}$

\begin{tabular}{|c|c|c|c|c|c|c|}
\hline $\begin{array}{c}\text { Inhibitor } \\
\text { Level }\end{array}$ & $\begin{array}{c}\text { Statistical } \\
\text { Parameters }\end{array}$ & $\begin{array}{c}\mathbf{E}_{\mathbf{b}} \\
(\mathbf{m V})\end{array}$ & $\begin{array}{l}E_{\text {corr }} \\
(\mathbf{m V})\end{array}$ & $\begin{array}{c}I_{p} \\
\left(\mu \mathrm{A} / \mathbf{c m}^{2}\right)\end{array}$ & $\begin{array}{c}E_{\text {pol }} \\
(\mathrm{mV})\end{array}$ & $\begin{array}{c}I \text { at } E_{p o l} \\
\left(\mu \mathrm{A} / \mathbf{c m}^{2}\right)\end{array}$ \\
\hline \multirow[t]{2}{*}{ Low } & Range & $\begin{array}{c}-10 \text { to }- \\
250\end{array}$ & $\begin{array}{c}-275 \text { to }- \\
432\end{array}$ & 1 to 40 & \multirow[t]{2}{*}{+0} & \multirow[t]{2}{*}{2 to $>200$} \\
\hline & Average & -87 & -353 & 12 & & \\
\hline \multirow[t]{2}{*}{ Medium } & Range & $\begin{array}{c}+150 \text { to }- \\
25\end{array}$ & $\begin{array}{c}-300 \text { to }- \\
423\end{array}$ & 8.5 to 70 & \multirow[t]{2}{*}{+140} & \multirow[t]{2}{*}{90} \\
\hline & Average & +38 & -345 & 30 & & \\
\hline \multirow[t]{2}{*}{ High } & Range & $\begin{array}{l}+115 \text { to } \\
+100\end{array}$ & $\begin{array}{c}-279 \text { to }- \\
436\end{array}$ & 5 to 20 & \multirow[t]{2}{*}{+200} & \multirow[t]{2}{*}{50} \\
\hline & Average & +108 & -370 & 14 & & \\
\hline
\end{tabular}

Table 6. Summarized CPP Data For Freshly Polished Samples at $25^{\circ} \mathrm{C}$

\begin{tabular}{|c|c|c|c|c|c|c|}
\hline $\begin{array}{c}\text { Inhibitor } \\
\text { Level } \\
\end{array}$ & $\begin{array}{c}\text { Statistical } \\
\text { Parameters }\end{array}$ & $\begin{array}{c}\mathbf{E}_{\mathbf{b}} \\
(\mathbf{m V})\end{array}$ & $\begin{array}{l}E_{\text {corr }} \\
(\mathrm{mV})\end{array}$ & $\begin{array}{c}I_{p} \\
\left(\mu \mathrm{A} / \mathrm{cm}^{2}\right)\end{array}$ & $\begin{array}{c}E_{\text {pol }} \\
(\mathrm{mV})\end{array}$ & $\begin{array}{c}\text { I at } E_{\text {pol }} \\
\left(\mu \mathrm{A} / \mathbf{c m}^{2}\right)\end{array}$ \\
\hline \multirow[t]{2}{*}{ Low } & Range & $\begin{array}{c}+123 \text { to }- \\
42\end{array}$ & $\begin{array}{c}-222 \text { to }- \\
333\end{array}$ & 0.7 to 6.7 & \multirow[t]{2}{*}{+140} & \multirow[t]{2}{*}{3 to $>200$} \\
\hline & Average & +36 & -285 & 3.1 & & \\
\hline \multirow[t]{2}{*}{ Medium } & Range & $\begin{array}{c}+239 \text { to } \\
+27\end{array}$ & $\begin{array}{c}-305 \text { to }- \\
450\end{array}$ & 0.2 to 10 & \multirow[t]{2}{*}{+185} & \multirow[t]{2}{*}{20} \\
\hline & Average & +86 & -380 & 5.6 & & \\
\hline \multirow[t]{2}{*}{ High } & Range & $\begin{array}{l}+152 \text { to } \\
+100\end{array}$ & $\begin{array}{c}-227 \text { to }- \\
510\end{array}$ & 2 to 7 & \multirow[t]{2}{*}{+225} & \multirow[t]{2}{*}{20} \\
\hline & Average & +125 & -347 & 4.7 & & \\
\hline
\end{tabular}

As mentioned previously, $\mathrm{E}_{\mathrm{pol}}$ must be selected so that the potential to which the U-bend is polarized is not within the passive regime, yet not so high above $\mathrm{E}_{\mathrm{b}}$ that the generated current results in excessive general corrosion. As a first estimate for $\mathrm{E}_{\mathrm{pol}}$, a value approximately $100 \mathrm{mV}$ above the average $\mathrm{E}_{\mathrm{b}}$ was examined (see data in Table 5 for $50^{\circ} \mathrm{C}$ ). In most cases the current density at $\mathrm{E}_{\mathrm{pol}}$ was 2 to 5 times greater than $\mathrm{I}_{\mathrm{p}}$. There were 3 cases out of the more than 30 tests where the current density exceeded $200 \mu \mathrm{A} / \mathrm{cm}^{2}$, which occurred at the low inhibitor concentration. Ondrejcin in previous SCC testing utilized an applied current density of 0.2 $\mathrm{A} / \mathrm{cm}^{2}$ (or $200 \mu \mathrm{A} / \mathrm{cm}^{2}$ ), but a later reference indicated that this current density may be too aggressive [12.]. If $\mathrm{E}_{\mathrm{pol}}$ is lowered, for example to the average $\mathrm{E}_{\mathrm{b}}$, it is possible that the sample will remain in the passive regime rather than in the passive to active transition region where SCC is most likely to occur. If the sample were to remain in the passive regime, a false positive result may be obtained. Thus as a first estimate an $E_{p o l}$ of approximately $100 \mathrm{mV}$ above the $E_{b}$ should be utilized for the polarized U-bend tests. 
WSRC-STI-2006-00029

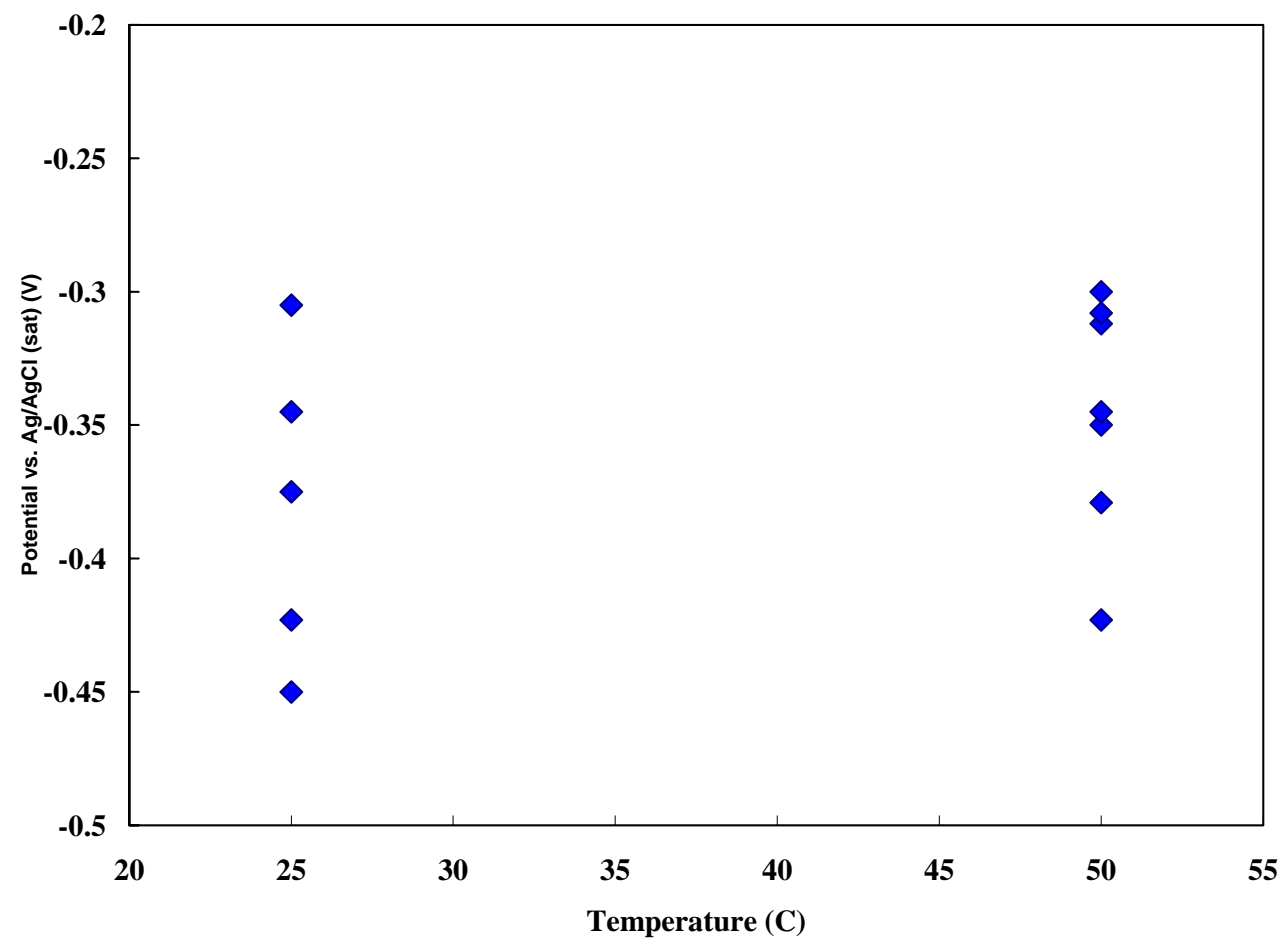

Figure 11. Plot demonstrating that $E_{\text {corr }}$ is independent of temperature

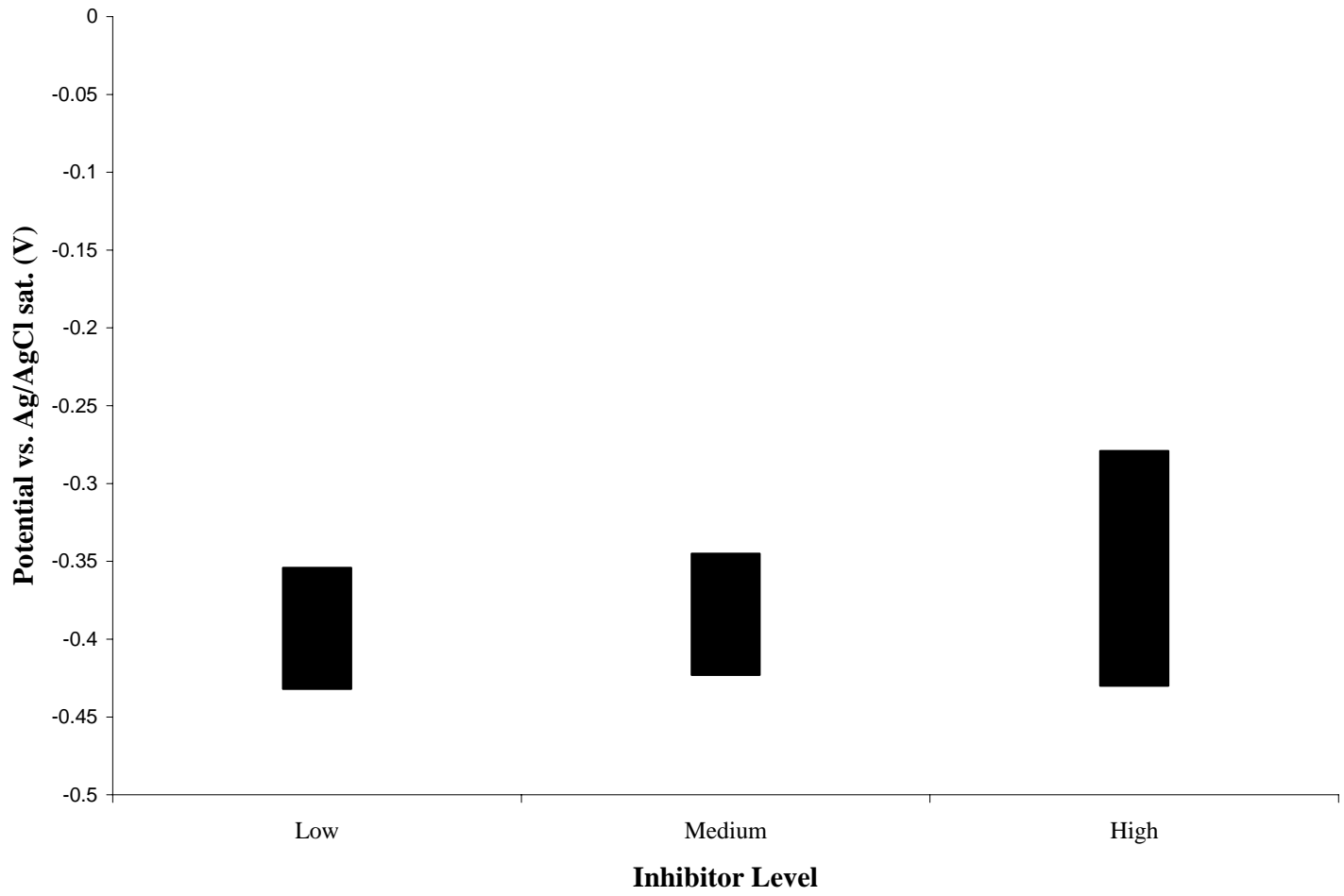

Figure 12. Plot demonstrating that $E_{c o r r}$ is independent of inhibitor concentration level 
Cyclic polarization tests were also performed on samples that had been immersed in test solutions for a week. The samples were removed from the solution and placed in fresh test solutions for the CPP tests. Although there was considerable scatter in the data, several differences between the electrochemical behavior for the monitored samples and the polished samples were observed. $\mathrm{E}_{\text {corr }}$ still did not demonstrate a dependence on nitrate concentration or temperature, however it did show a dependence upon the inhibitor concentration level. Table 7 shows that at the low and medium inhibitor concentration the average values for $\mathrm{E}_{\text {corr }}$ were not significantly different than the values observed for the polished samples ( $-450 \mathrm{mV}$ to $-300 \mathrm{mV}$ ). However, at the high inhibitor concentration level, the data indicate that $\mathrm{E}_{\text {corr }}$ shifts towards a more positive potential and into the passive regime.

The temperature and inhibitor concentration level had a significant effect on the $\mathrm{E}_{\mathrm{b}}$. It should be noted that if the value of $E_{b}$ is greater that $+430 \mathrm{mV}$, the specimen exhibited passive behavior. In this case, $\mathrm{E}_{\mathrm{b}}$ is more accurately called the transpassive potential (see Figure 6, 8.5 M nitrate at high inhibitor concentration level). In this region the rapid increase in current is due to a reaction other than metal dissolution, most typically oxygen evolution. The results in Table 7 indicate that at the high inhibitor concentration level the oxide film does not breakdown at $25^{\circ} \mathrm{C}$ or 50 ${ }^{\circ} \mathrm{C}$. The same observation is made for the medium inhibitor concentration level at $25^{\circ} \mathrm{C}$. At 50 ${ }^{\circ} \mathrm{C}$, however, the results were mixed for the medium inhibitor concentration level as one of the samples exhibited an $E_{b}$, while the other three samples exhibited passive behavior. The same mixed behavior was observed at the low inhibitor concentration level at $25^{\circ} \mathrm{C}$ as two of the four samples exhibited an $\mathrm{E}_{\mathrm{b}}$. At $50^{\circ} \mathrm{C}$ all four samples at the low inhibitor concentration level exhibited an $E_{b}$. The $E_{b}$ in this case is approximately $150 \mathrm{mV}$ more positive than that for the freshly polished sample.

The Ip of the exposed samples was 2 to 10 times less than polished samples exposed to the same environment. The results in Table 7 illustrate that $I_{p}$ decreases with an increase in the inhibitor concentration level and a decrease in temperature. It should be noted that the passive current densities that are observed, particularly at the medium and high inhibitor concentrations are extremely low and indicate a low degree of corrosive activity.

The results of the CPP tests performed on the exposed samples consistently demonstrate that the metal formed a protective oxide film during extended exposure to each of these environments. The tenacity of this film improved as the inhibitor concentration level was increased and the temperature was decreased. The results suggest that if the metal was exposed to a waste environment that had an inhibitor concentration greater than the medium level for a long time, that subsequent exposure to a dissolved salt solution with at least the medium inhibitor concentration should not result in the breakdown of the passive oxide film. However, the tests do not show that if the dissolved salt solution had an inhibitor concentration at the low level, this solution would cause the passive film that was formed at the higher inhibitor levels to break down. The next series of electrochemical tests will address this issue. 
Table 7. Summary Data from CPP tests Performed on Previously Exposed Samples

\begin{tabular}{|c|c|c|c|c|c|}
\hline & $\begin{array}{c}\text { Inhibitor } \\
\text { Level }\end{array}$ & $\begin{array}{l}\text { Statistical } \\
\text { Parameters }\end{array}$ & $\mathrm{E}_{\mathrm{b}}(\mathrm{mV})$ & $\mathrm{E}_{\text {corr }}(\mathrm{mV})$ & $\begin{array}{l}\text { Passive } \\
\text { Current } \\
\text { Density } \\
\left(\mu \mathrm{A} / \mathrm{cm}^{2}\right)\end{array}$ \\
\hline \multirow[t]{6}{*}{50} & \multirow[t]{2}{*}{ Low } & Range & +80 to +50 & -227 to -680 & 0.8 to 18 \\
\hline & & Average & +64 & -438 & 7 \\
\hline & \multirow[t]{2}{*}{ Medium } & Range & +503 to +5 & -226 to -445 & 0.5 to 5 \\
\hline & & Average & +336 & -332 & 2.8 \\
\hline & \multirow[t]{2}{*}{ High } & Range & +540 to +431 & -127 to -234 & 0.1 to 3 \\
\hline & & Average & +494 & -183 & 1.4 \\
\hline \multirow[t]{6}{*}{25} & \multirow[t]{2}{*}{ Low } & Range & +571 to +128 & -382 to -528 & 0.8 to 11 \\
\hline & & Average & +355 & -451 & 6.2 \\
\hline & \multirow[t]{2}{*}{ Medium } & Range & +603 to +512 & -324 to -371 & 0.2 to 0.9 \\
\hline & & Average & +565 & -346 & 0.6 \\
\hline & \multirow[t]{2}{*}{ High } & Range & +543 to +486 & -175 to -360 & 0.2 to 0.7 \\
\hline & & Average & +520 & -235 & 0.4 \\
\hline
\end{tabular}

\section{Pitting data}

Figures 13 through 16 show the results for the CPP scans. The important potential parameters $\left(\mathrm{E}_{\mathrm{corr}}, \mathrm{E}_{\mathrm{b}}\right.$, and $\mathrm{E}_{\mathrm{rp}}$ ) are plotted against the hydroxide concentration (Note: 0.01 M hydroxide corresponds to the low inhibitor concentration level). The potential data represent an average of 3 to 7 datapoints. The range for each of the average values is $\pm 100 \mathrm{mV}$. An arrow on the $E_{b}$ value that points toward more electropositive potentials indicates that some of the samples tested in that environment exhibited passive behavior while others exhibited localized corrosion. This behavior suggests that the passive film is weak. An arrow on the $\mathrm{E}_{\mathrm{rp}}$ value that points toward more electronegative potentials is indicative that most of the samples tested in that environment exhibited potentials that were typically more electronegative than $\mathrm{E}_{\text {corr }}$. This behavior is typically observed when crevice corrosion is observed on the sample. It should also be noted that if no values for $E_{b}$ or $E_{r p}$ are shown, passive behavior was observed. That is, either positive hysterisis was observed or $\mathrm{E}_{\mathrm{co}}$ was greater than the $\mathrm{E}_{\mathrm{t}}$.

Figures 13 and 14 are the results of the CPP scans for the polished samples. At $25{ }^{\circ} \mathrm{C}$ and $50{ }^{\circ} \mathrm{C}$, localized corrosion (i.e., crevice and pitting) was observed at both the low and medium inhibitor concentration levels. Examples of this attack are shown in Figure 17. The results in Figures 13 and 14 show that the difference between $\mathrm{E}_{\mathrm{b}}$ and $\mathrm{E}_{\text {corr }}$ increases as the inhibitor concentration level increases. Likewise, the difference between $\mathrm{E}_{\mathrm{rp}}$ and $\mathrm{E}_{\text {corr }}$ also increases. A temperature effect was also observed as these differences increased as the temperature was decreased. 


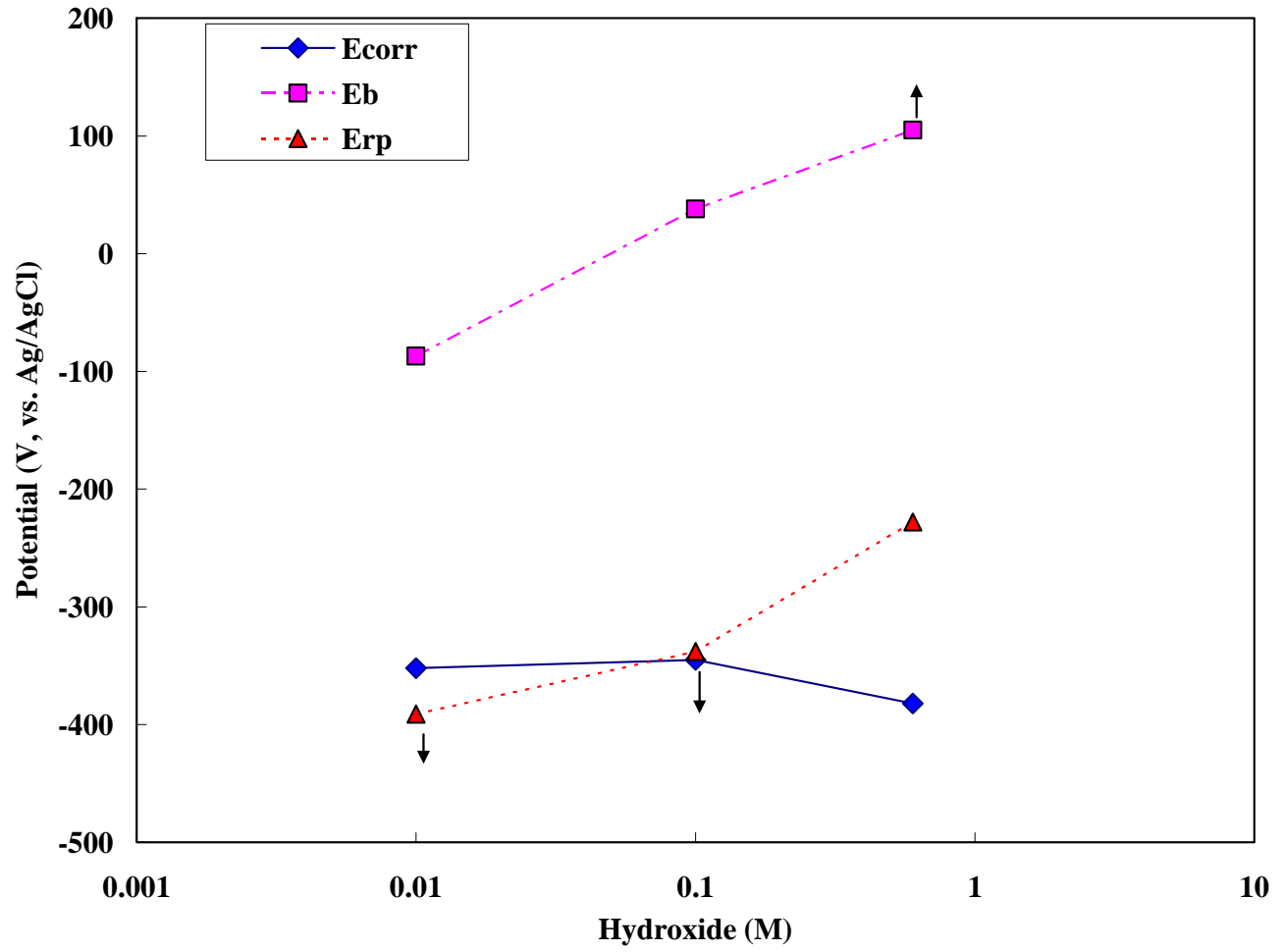

Figure 13. Relationship between $E_{c o r r}, E_{b}$, and $E_{r p}$ for polished samples at $50{ }^{\circ} \mathrm{C}$

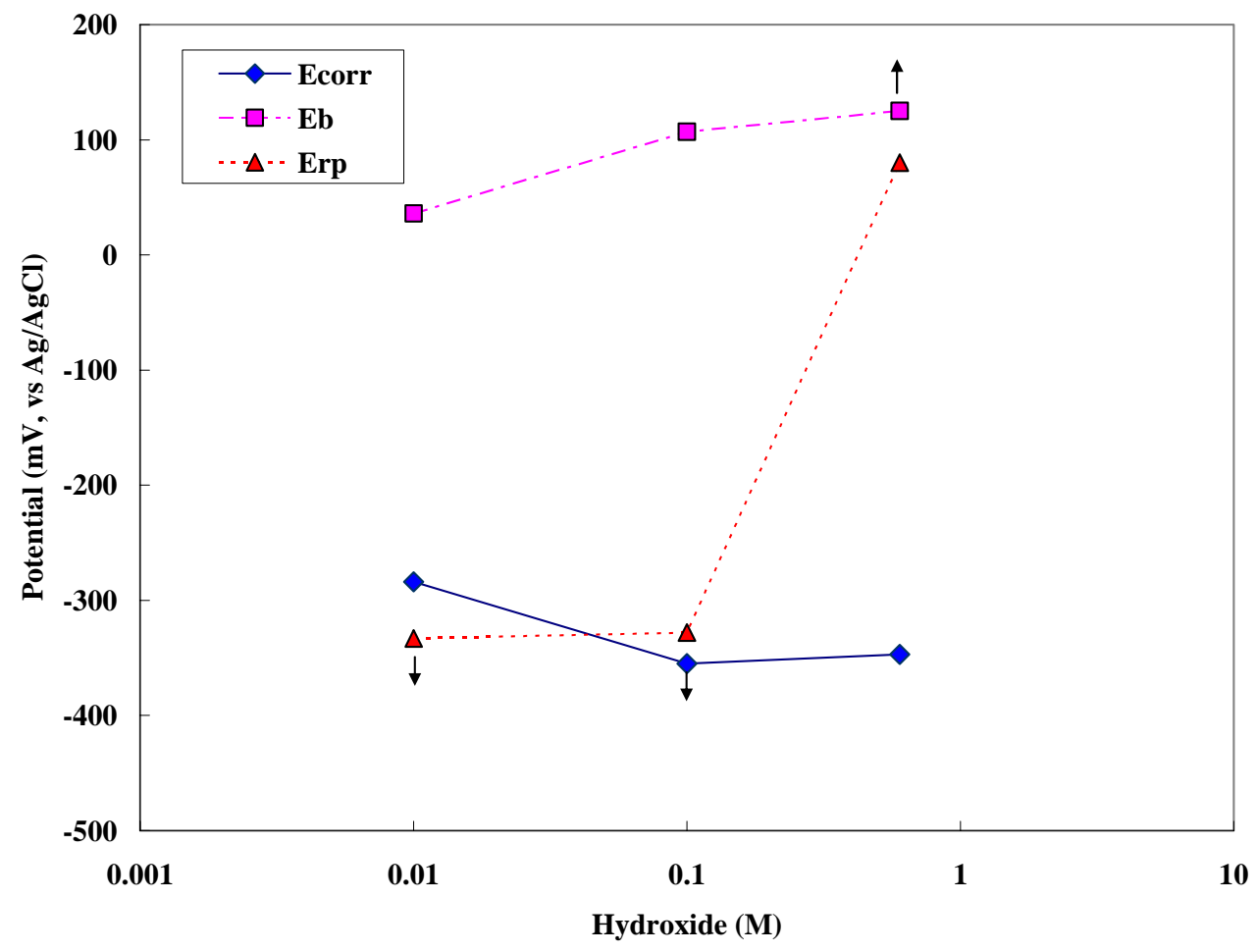

Figure 14. Relationship between $E_{c o r r}, E_{b}$, and $E_{r p}$ for polished samples at $25{ }^{\circ} \mathrm{C}$. Note the 0.01 M hydroxide tests correspond to the low inhibitor concentration level, etc. 
The results for the high inhibitor concentration level tests were mixed as some samples exhibited passive behavior, while others exhibited pitting behavior. At $50{ }^{\circ} \mathrm{C}, 3$ of the 5 samples exhibited passive behavior, while at $25^{\circ} \mathrm{C}$, 2 of the 3 samples exhibited passive behavior. These results suggest that if a bare metal surface is present on the tank wall, that location would be susceptible to localized corrosion at any of these inhibitor concentration levels tested thus far. However, the risk of localized corrosion at inhibitor concentrations greater than the medium level and at lower temperatures is significantly reduced.

Figures 15 and 16 are the results of the CPP scans for the previously exposed samples. At $50{ }^{\circ} \mathrm{C}$, the results for the low and medium inhibitor concentration levels were mixed. In the case of the low inhibitor level 2 of the 4 samples pitted, while for the medium inhibitor level, 1 of 3 samples pitted. At the high inhibitor level, passive behavior was observed. At $25{ }^{\circ} \mathrm{C}$, the resistance to localized corrosion increased. No localized attack was observed on a sample at any of the inhibitor levels. $E_{b}$ or $E_{r p}$ were not observed for the medium and high inhibitor concentrations. Although $\mathrm{E}_{\mathrm{co}}$ was observed in many cases, it was typically at a potential more electronegative than $E_{t}$ suggesting a protective oxide film is present. However, two of the samples at the low inhibitor concentration had values for $\mathrm{E}_{\mathrm{b}}$ and an $\mathrm{E}_{\mathrm{co}}$ that indicated the passive oxide film was not as protective in this environment.

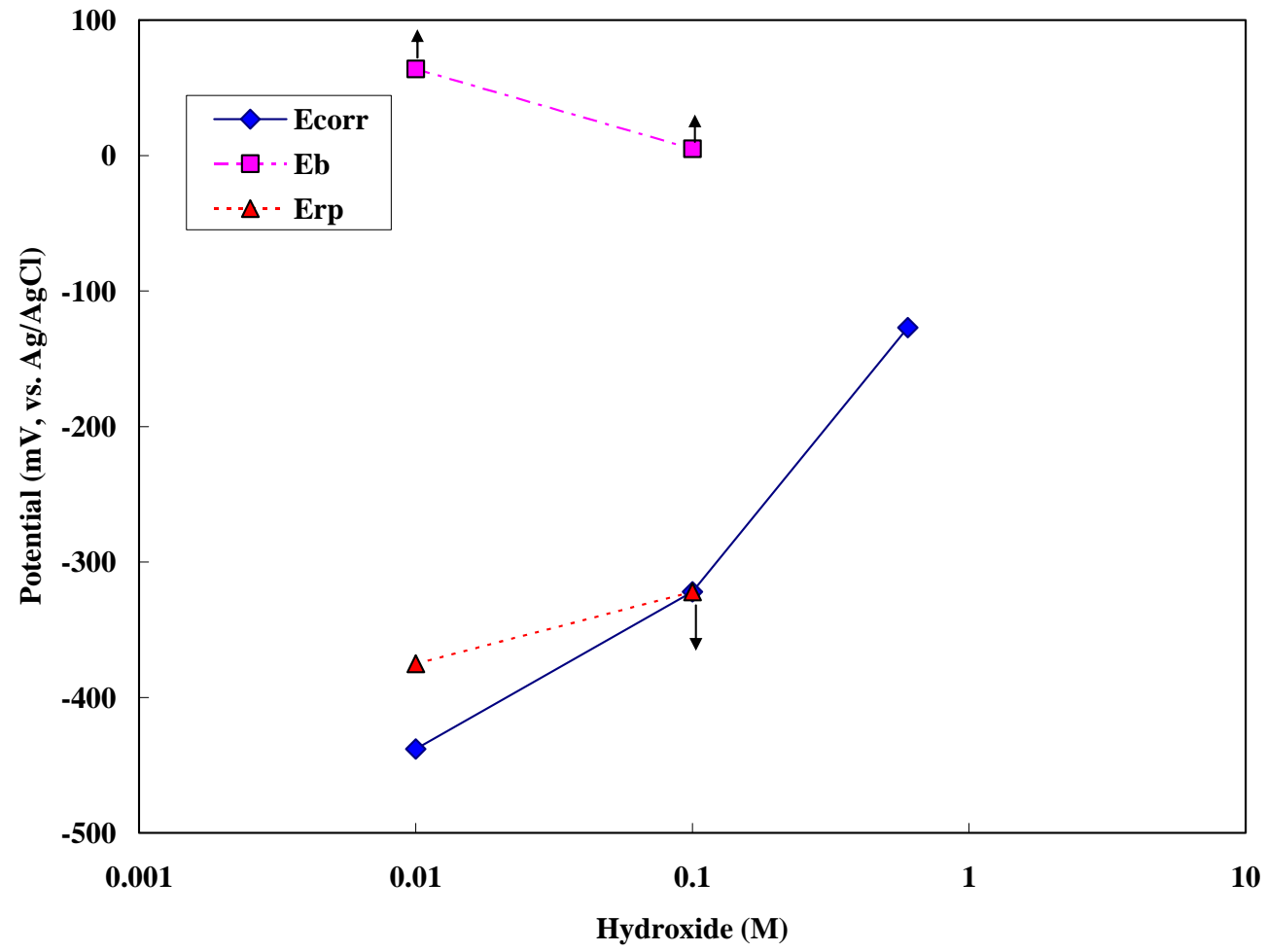

Figure 15. Relationship between $E_{c o r r}, E_{b}$, and $E_{r p}$ for exposed samples at $50{ }^{\circ} \mathrm{C}$ for low (0.01 M OH), medium (0.1 M OH) and high (0.6 M OH) inhibitor levels

A comparison between the results for the polished samples and the previously exposed samples demonstrate that if the metal has been passivated, the resistance to localized corrosion increased 
significantly. Previous exposure of the sample to inhibitor concentration levels greater than the medium level provides a protective oxide film with passive behavior in environments that contain inhibitor concentrations greater than the medium level. Even at the low inhibitor concentration level, a significant increase in resistance was observed. Given that the tank walls have been exposed to inhibitor concentration levels significantly higher than in these tests, these tests would provide a more realistic simulation of the actual corrosion behavior of the tank material than the tests performed on the polished samples. The tests on the freshly polished samples would provide the most conservative results. The tests do not show that if a passive film formed with a higher inhibitor concentration would break down in a salt solution with a low level of inhibitor. The next series of electrochemical tests will address this issue.

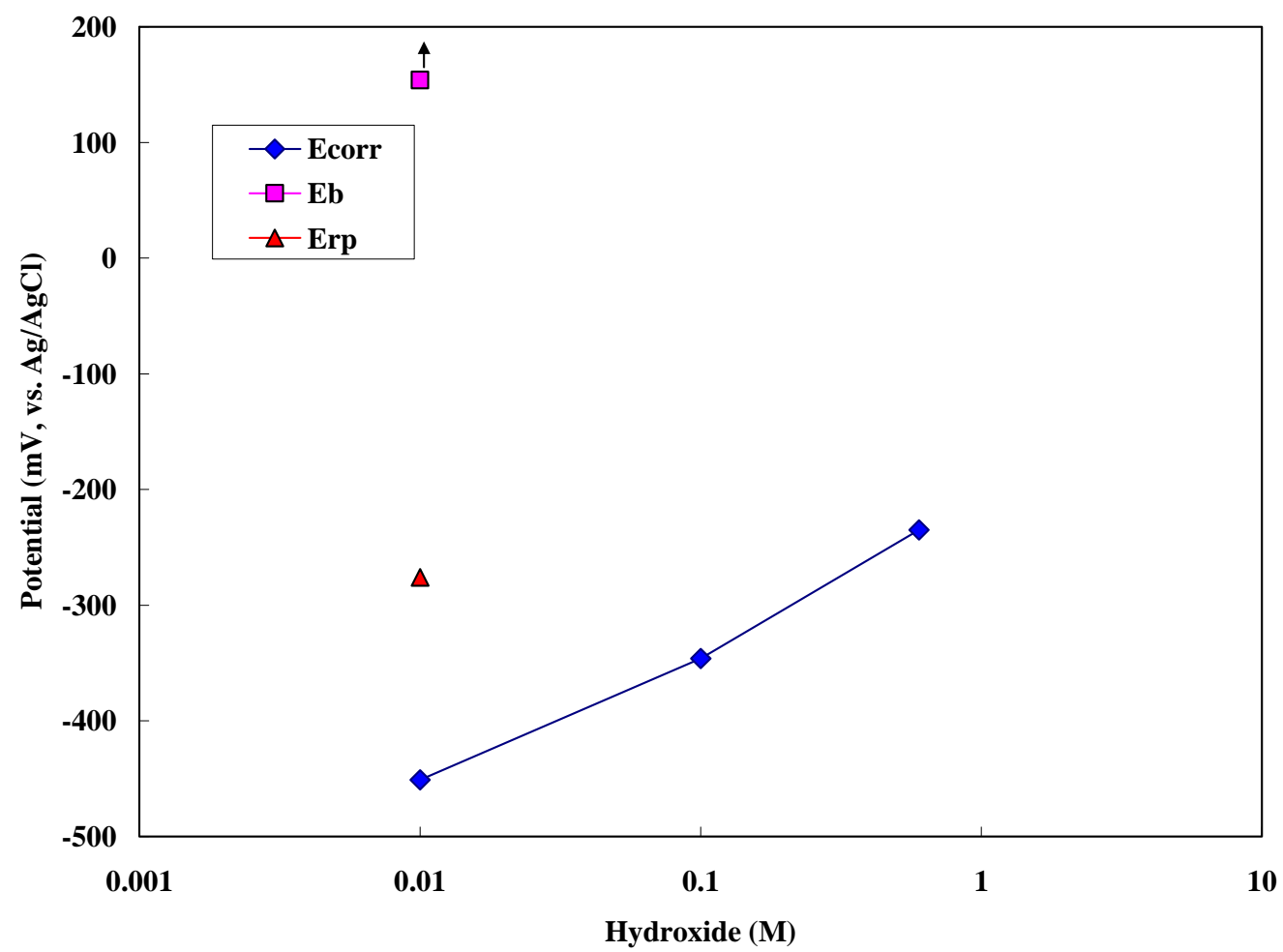

Figure 16. Relationship between $E_{c o r r}, E_{b}$, and $E_{r p}$ for exposed samples at $25{ }^{\circ} \mathrm{C}$ for low (0.01 M OH), medium (0.1 M OH) and high (0.6 M OH) inhibitor levels

\section{Open Circuit Potential}

Figure 18 shows examples of the type of results that were obtained from OCP monitoring. In general, the OCP increased for a period of 2 to 3 days and then achieved a stable value. This behavior indicates that an oxide film is building up on the material surface. The increase in the OCP tended to be greater for the $50{ }^{\circ} \mathrm{C}$ tests than that for the $25^{\circ} \mathrm{C}$. In fact, at lower temperatures there were cases where the OCP remained relatively constant or even decreased. Although the initial OCP did not have a strong dependence on inhibitor concentration level or temperature, the final OCP appears to have a slight dependence on both of these variables. The OCP appears to become more electropositive with an increase in temperature and inhibitor level concentration. Both of these observations indicate the build-up of the oxide film. 


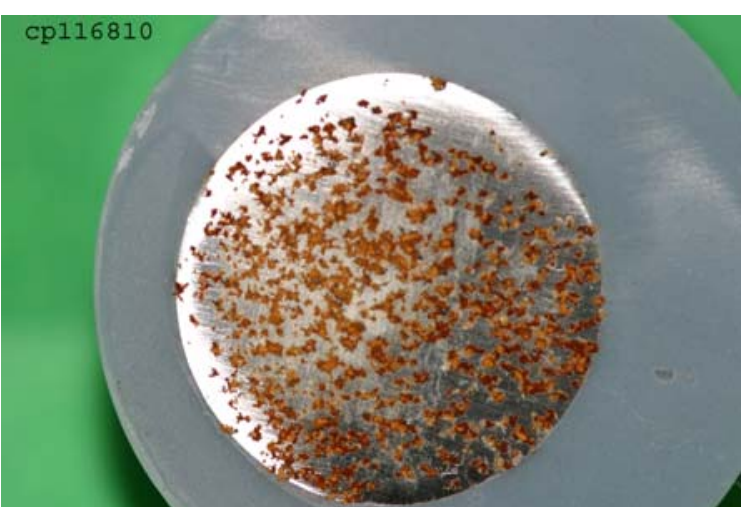

(A)

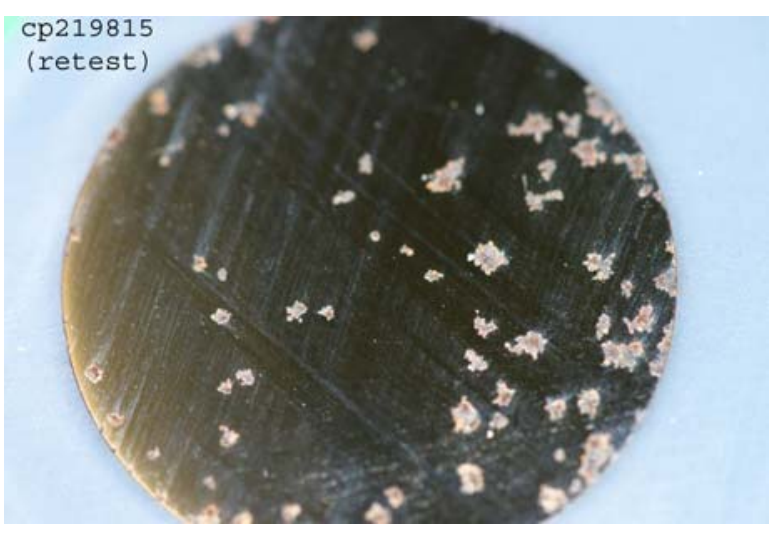

(B)

Figure 17. Photographs of pitting and crevice attack that occurred during the CPP scan in solutions of $5.5 \mathrm{M}$ nitrate at $50 \mathrm{C}$ with (A) low inhibitor and (B) medium inhibitor concentrations.

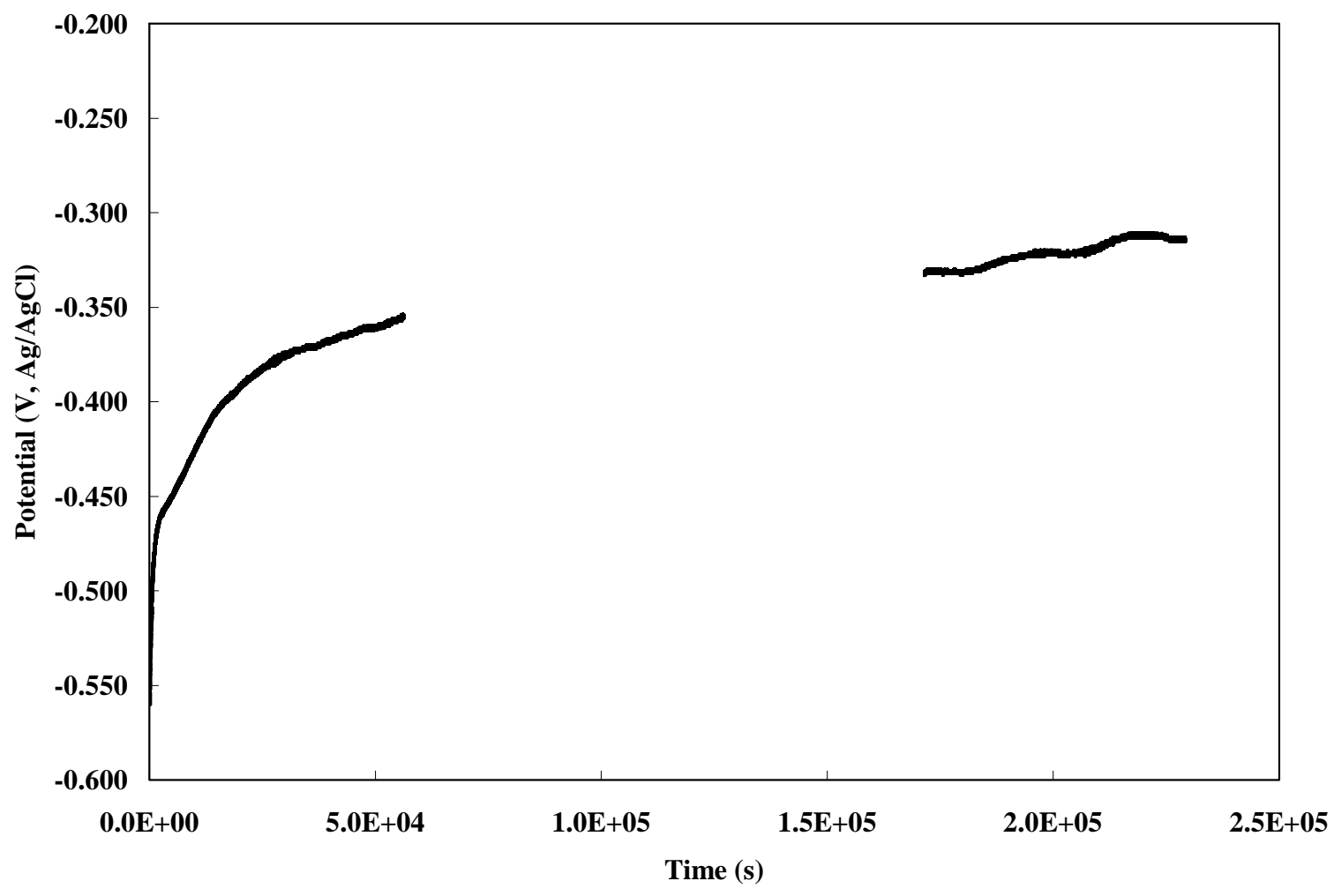

Figure 18. Plot of OCP data for $5.5 \mathrm{M}$ nitrate solution, low inhibitor concentration at 25 ${ }^{\circ} \mathrm{C}$. The gap indicates where data was not collected for approximately 30 hours.

The initial OCP is similar to the value for Ecorr measured by the CPP tests for the freshly polished samples, while the final OCP is similar to the value for Ecorr measured by the CPP tests 
for the exposed samples. Thus the conclusions made with regard to the susceptibility of the bare metal surface and surface with a passive oxide should be similar. This can be demonstrated by examining the results for the previously exposed samples. Table 8 shows the final OCP compared with the $\mathrm{E}_{\mathrm{b}}$ and $\mathrm{E}_{\mathrm{rp}}$ measured from the previously exposed samples. At $50{ }^{\circ} \mathrm{C}$, the observations that there is a relatively small difference between $E_{b}$ and OCP and that $E_{\mathrm{rp}}$ is less than the final OCP indicate that carbon steel may be susceptible to localized corrosion, particularly crevice corrosion, at the low and medium inhibitor concentration levels. At the high inhibitor concentration levels there was no indication of susceptibility to localized corrosion. At $25{ }^{\circ} \mathrm{C}$, there was an indication of the possibility of crevice attack at the low inhibitor concentration. The $\mathrm{E}_{\mathrm{rp}}$ for the $5.5 \mathrm{M}$ nitrate test was within $200 \mathrm{mV}$ of the final OCP at that concentration. However, for the most part the tests at this temperature indicate that at $25{ }^{\circ} \mathrm{C}$, the material is not susceptible to localized corrosion at these inhibitor levels. This conclusion is corroborated by the observation that no evidence of attack was observed for any of the CPP tests on previously exposed samples at $25^{\circ} \mathrm{C}$.

Table 8. OCP Measurements

\begin{tabular}{|c|c|c|c|c|c|c|}
\hline $\begin{array}{c}\text { Temperature } \\
\text { (C) }\end{array}$ & $\begin{array}{c}\text { Inhibitor } \\
\text { Level }\end{array}$ & $\begin{array}{c}\text { Nitrate } \\
\text { (M) }\end{array}$ & $\begin{array}{c}\text { Initial OCP } \\
(\mathrm{mV})\end{array}$ & $\begin{array}{c}\text { Final OCP } \\
(\mathrm{mV})\end{array}$ & $\begin{array}{c}E_{b} \\
(m V)\end{array}$ & $\begin{array}{c}E_{r p} \\
(\mathrm{mV})\end{array}$ \\
\hline \multirow[t]{6}{*}{50} & \multirow[t]{2}{*}{ Low } & 5.5 & -308 & -106 & +64 & -375 \\
\hline & & 7.0 & -216 & -175 & NA & NA \\
\hline & \multirow[t]{2}{*}{ Medium } & 5.5 & -322 & -178 & +5 & -445 \\
\hline & & 7.0 & -211 & -167 & NA & NA \\
\hline & \multirow[t]{2}{*}{ High } & 5.5 & -325 & -77 & NA & NA \\
\hline & & 7.0 & -85 & -40 & NA & NA \\
\hline \multirow[t]{6}{*}{25} & \multirow[t]{2}{*}{ Low } & 5.5 & -577 & -298 & +154 & -260 \\
\hline & & 7.0 & -361 & -318 & NA & NA \\
\hline & \multirow[t]{2}{*}{ Medium } & 5.5 & -269 & -354 & NA & NA \\
\hline & & 7.0 & -264 & -264 & NA & NA \\
\hline & \multirow[t]{2}{*}{ High } & 5.5 & -479 & -294 & NA & NA \\
\hline & & 7.0 & -256 & -260 & NA & NA \\
\hline
\end{tabular}

$\mathrm{NA}-\mathrm{An} \mathrm{E}_{\mathrm{b}}$ or $\mathrm{E}_{\mathrm{rp}}$ was not identified. Passive behavior was observed.

\section{General Corrosion}

The initial general corrosion rate on the samples was typically 1 to $3 \mathrm{mpy}$. The data showed that the corrosion rate decreased with exposure time to a relatively stable corrosion rate after 2 or 3 days. Table 9 shows the range of stable general corrosion rates that were measured as a function of nitrate concentration, temperature, and inhibitor concentration. Nearly all of the general corrosion rates were less than $1 \mathrm{mpy}$. The data indicate that there is a tendency towards higher general corrosion rates at the higher temperature and lower inhibitor concentration levels. These low general corrosion rates are consistent with the general corrosion rate of $1 \mathrm{mpy}$ that was assumed for estimation of the tank service life [13]. Therefore if any of these inhibitor levels are selected for storage of dissolved salt solutions, no changes to the service life estimates that were based on general corrosion are necessary. 
WSRC-STI-2006-00029

Table 9. General Corrosion Rates at the Stable Open Circuit Potentials

\begin{tabular}{|c|c|c|c|c|}
\hline $\begin{array}{c}\text { Temperature } \\
\left({ }^{\circ} \mathbf{C}\right)\end{array}$ & $\begin{array}{c}\text { Nitrate } \\
(\mathbf{M})\end{array}$ & $\begin{array}{c}\text { Corrosion Rate } \\
\text { Low Inhibitor } \\
\text { (mpy) }\end{array}$ & $\begin{array}{c}\text { Corrosion Rate } \\
\text { Medium Inhibitor } \\
\text { (mpy) }\end{array}$ & $\begin{array}{c}\text { Corrosion Rate } \\
\text { High Inhibitor } \\
\text { (mpy) }\end{array}$ \\
\hline 25 & 5.5 & 0.11 to 0.27 & 0.23 to 0.26 & 0.022 to 0.033 \\
\hline 25 & 7.0 & 0.41 to 0.83 & 0.19 to 0.32 & 0.22 to 0.45 \\
\hline 50 & 5.5 & 0.05 to 0.2 & 0.1 to 1.24 & 0.031 to 0.044 \\
\hline 50 & 7.0 & 0.13 to 1.42 & 0.08 to 0.49 & 0.03 to 0.20 \\
\hline
\end{tabular}

\section{Polarized U-bend Testing}

Prior to performing the polarized U-bend tests with waste simulants, tests were performed in more aggressive solutions without inhibitors at high temperatures to prove the technique. The test solution was $7 \mathrm{M}$ sodium nitrate and the applied potential was $0.0 \mathrm{~V}$. The first test was performed at $50{ }^{\circ} \mathrm{C}$. The test was run for over three days without the U-bend cracking, although cracking may have occurred at longer times. The next tests consisted of two U-bends with or with out a precut crack. The precut sample was used to facilitate the likelihood of cracking. These tests were performed at $95{ }^{\circ} \mathrm{C}$ and an applied potential of $0.0 \mathrm{~V}$. Both samples cracked within two days. The precut U-bend cracked after 49 hours and the uncut U-bend cracked within approximately one day. The precut crack did not accelerate the attack as expected, which probably due to its bluntness failed to effectively increase the applied stress intensity. This variation in time to failure is inherent to U-bend testing.

Preliminary tests were also performed on heat-treated samples, following the stress relieving regime. These U-bends were also tested in $7 \mathrm{M}$ nitrate solution at $95{ }^{\circ} \mathrm{C}$ with an applied potential of $0.0 \mathrm{~V}$ versus $\mathrm{Ag} / \mathrm{AgCl}$. Both of these tests were stopped because of experimental difficulties, but ran for over two weeks without any cracks. During these tests, frequent current increases were investigated by removing the sample from testing and inspecting for cracks. The U-bends were then returned to test. These frequent removals are associated with the eventual stopping of the test.

For the second test series, polarized U-bends, as-received and stress relieved, were performed in the various nitrate solutions at low inhibitor concentrations $(0.01 \mathrm{M}$ hydroxide and $0.01 \mathrm{M}$ nitrite) to assess those chemistries with the highest probability of stress corrosion cracking failure. These tests were run for eighteen weeks. These tests were not interrupted in order to minimize disturbances that might lead to test failure as experienced in the preliminary test series. Several equipment failures, however, did occur which resulted in the samples being unpolarized for short periods and receiving large current spikes each time the potential was applied. The longest unpolarized period was approximately five days. When the samples were unpolarized, they remained at the desired test temperature.

The U-bends that cracked during this test were all those in the as-received condition. The stress relieved U-bends did not crack. Figure 19 shows photographs of both the as-received and stress 
relieved U-bends after testing in the $4.5 \mathrm{M}$ solution. Figure 20 shows the as-received U-bend with the exposed crack surface. In Figure 19, the crack from the exterior surface is clearly evident for the as-received U-bend.

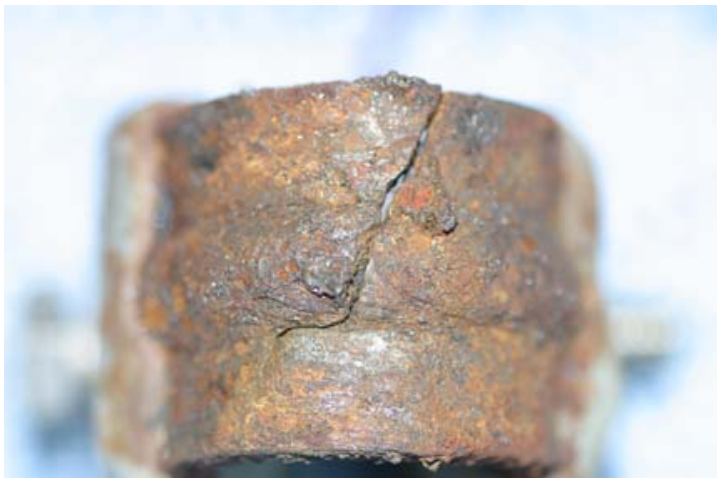

(A)

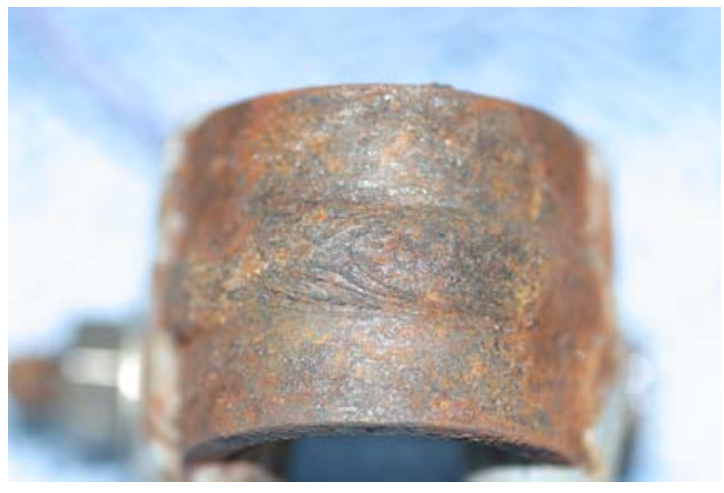

(B)

Figure 19. Photographs of the As-received (A) and Heat-treated (B) U-bend After Testing in $4.5 \mathrm{M}$ nitrate Solution at $50^{\circ} \mathrm{C}$
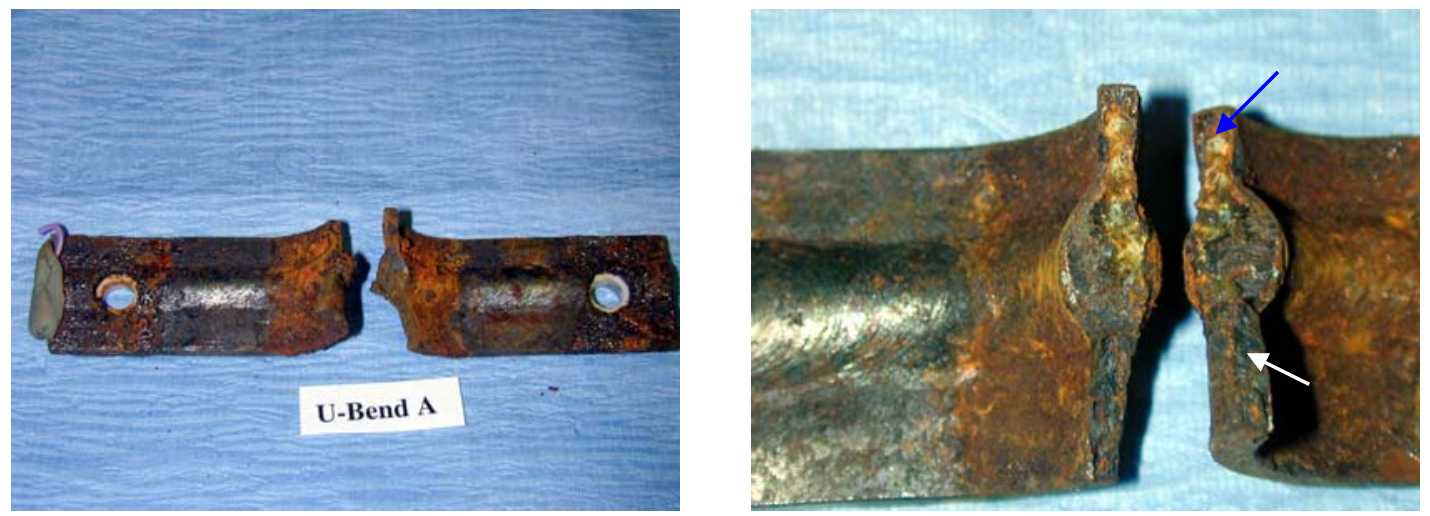

Figure 20. Photographs of U-bend After Testing in 4.5 M Nitrate Solution

The corrosion and fracture morphology of the cracked surface indicates that the U-bend failed in two modes or at two times. The blue arrow shows the surface covered with a reddish/brown corrosion product layer, which appears rough. The second region, indicated by the white arrow appears to have a black corrosion product layer, possibly magnetite. The blue arrow area is believed to have cracked first and with longer exposure and greater oxygen availability produced the redder corrosion product. The second region probably cracked in test with minimal separation of cracked surfaces and with minimal oxygen availability producing a magnetite layer. All the as-received U-bends had similar failure surfaces. The figure also shows that the epoxy layer at the liquid/vapor interface was effective in protecting the base metal. Only a small amount of crevice corrosion was found.

The heat treating may have two effects that are beneficial for minimizing or preventing cracking. A residual stress is put into the U-bend as a result of the welding process. The heat treatment 
may have relieved or reduced this stress state. The heat treatment also further oxidizes the surface and may provide a superior barrier to corrosion. As the test was structured, these two effects cannot be differentiated. Whichever mechanism is effective, the stress relieving heat treatment has clearly increased the SCC resistance of the Type III/IIIA waste tanks.

The initial applied potential, which was chosen from the cyclic polarization data, was $0.0 \mathrm{~V}$ versus Ag/AgCl. The initial potentials of the U-bends are shown in Table 10 and ranged from 0.325 to $-0.413 \mathrm{~V}$, which are similar to those from the electrochemical testing (Table 9). When this potential was applied all the samples produced anodic oxidizing currents. Over the course of the test, however, several samples had shifts in either the surface or solution conditions near the surface that resulted in cathodic currents being produced. This shift thereby protects the U-bend. Some samples had to have the potential adjusted several times. The as-received and heat-treated U-bends exposed to the 4.5 and 5.0 $\mathrm{M}$ nitrate solutions had these shifts in potential. For these samples, the applied potential was increased until anodic currents were maintained. Four to five weeks were used in reaching a stable current state. Samples exposed to the higher nitrate solutions $(7.0$ and $8.5 \mathrm{M}$ ) tended to remain anodic or cycle between the two states but remain anodic for the majority of the time. These data are summarized in the Table 11.

Table 10. Current State During Polarized U-bend Testing at $50{ }^{\circ} \mathrm{C}$

\begin{tabular}{|c|c|c|c|c|c|c|}
\hline Sample & Solution* & Type** & $\begin{array}{c}\text { OCP } \\
(\mathrm{V})\end{array}$ & State*** & $\begin{array}{c}\text { Current } \\
(\mathrm{uA})\end{array}$ & $\begin{array}{c}\text { Current Density } \\
\left(\mathrm{uA} / \mathrm{cm}^{2}\right)\end{array}$ \\
\hline H & $8.5 \mathrm{M}$ & HT & -0.325 & Cycled, 0 V & $20-100$ & $0.7-3.3$ \\
\hline D & & AR & -0.357 & Anodic, 0V & $50-250$ & $1.7-8.3$ \\
\hline G & $7.0 \mathrm{M}$ & HT & -0.413 & Cycled, 0V & $50-250$ & $1.7-8.3$ \\
\hline C & & AR & -0.370 & Anodic, 0V & $40-300$ & $1.3-10$ \\
\hline F & $5.5 \mathrm{M}$ & HT & -0.400 & Cathodic, 0.3 V & $10-500$ & $0.3-16.7$ \\
\hline B & & AR & -0.379 & Cathodic, 0.2 V & $50-100$ & $1.7-3.3$ \\
\hline E & $4.5 \mathrm{M}$ & HT & -0.375 & Cathodic, 0.3 V & $50-200$ & $1.7-6.7$ \\
\hline A & \multicolumn{7}{|c|}{ AR } & -0.391 & Cathodic, 0.3 V & $200-300$ & $6.7-10$ \\
\hline \multicolumn{7}{|c|}{$*$ molar concentration of nitrate } \\
$* *$ HT - heat treated, AR - as-received \\
** Current state at 0 V, final voltage to get anodic current
\end{tabular}

When the tests were first started currents ranged from 100-250mA and slowly declined during the first day to about 50-100 mA. The current levels slowly decreased to a range of 10-200 $\mu \mathrm{A}$ by the end of the tests. In Table 10, the currents are for the ranges of values during the later part of the test. In general, the current ranges were slightly higher for the as-received U-bends, which failed. The current densities were calculated using an average surface area of $30 \mathrm{~cm}^{2}$. The surface areas ranged from 28.1 to $30.9 \mathrm{~cm}^{2}$. The current densities fall within the range (2-200 $\mu \mathrm{A} / \mathrm{cm}^{2}$ ) from the CPP data for the low inhibitor level with the freshly prepared samples. From Table 7 for the previously exposed samples, $\mathrm{I}_{\mathrm{p}}$ was approximately $7 \mu \mathrm{A} / \mathrm{cm}^{2}$ for low inhibitor levels at $50{ }^{\circ} \mathrm{C}$. Only sample $\mathrm{H}$ had current densities that were below this value and would not be expected to crack. The heat treated U-bends in general had lower current densities than the as-received U-bends. 
The current scans for each of the U-bends were examined to determine at which time the asreceived U-bends had cracked. The current scans for the 7M nitrate samples, which were performed during the preliminary testing, were used as the basis for a crack (see Figure 9). The current scans for these more complex high nitrate solutions were difficult to evaluate since numerous peaks and plateaus occurred. Since sharp peaks were common in all the scans these changes were not associated with the cracking. The current scans where cracking is anticipated to have occurred are shown in Figure 21 for the three high nitrate solutions.

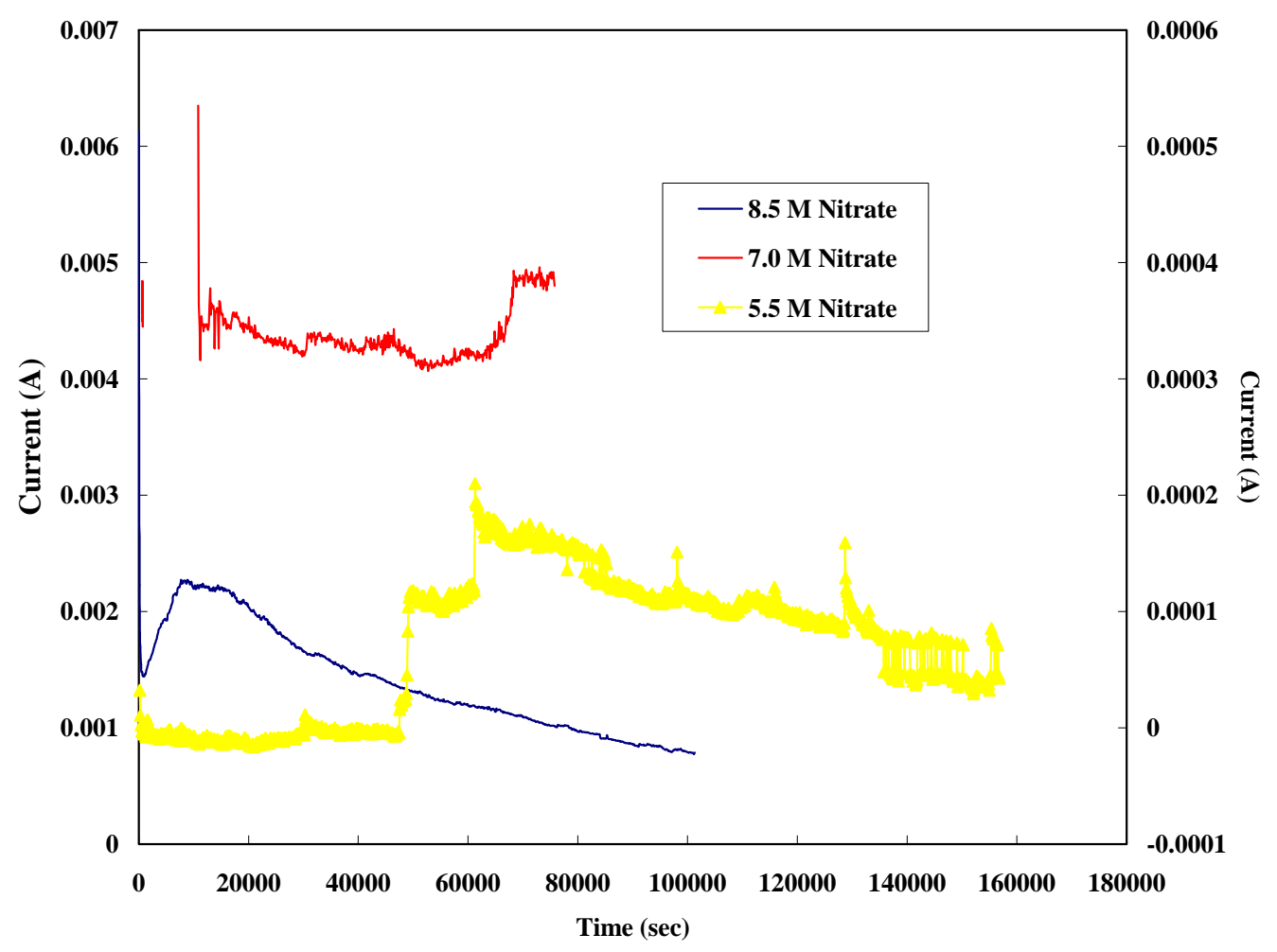

Figure 21. Current Scans For Cracking in As-Received U-bends at $50 \mathrm{C}$

The current scans associated with cracking differed in current change and time span. The current level and time to failure were a function of the nitrate concentration. The higher the nitrate concentration the shorter the time to failure and the larger the current levels at time of failure. The time to failures and corresponding nitrate concentrations were 13 days for $8.5 \mathrm{M}$ nitrate, 26 days for 7.0 M nitrate, 27 days for 5.5 M nitrate, and 85 days for 4.5 M nitrate.

In the third series, the 4.5 and $7.0 \mathrm{M}$ nitrate solution with low inhibitor were repeated to duplicate results. The $4.5 \mathrm{M}$ U-bend failed due to corrosion of the electrical contact. The $7 \mathrm{M}$ sample cracked in approximately 38 days. Another $4.5 \mathrm{M}$ test was set up and after four months had not failed. Although these samples lasted longer in test than the second series U-bends, the time to failure was still a function of the nitrate concentration.

For the remaining U-bends in the third series, a constant nitrate concentration of $7 \mathrm{M}$ was used and the inhibitor concentrations were as shown in Table 3. The polarization potentials were 
chosen from the cyclic polarization results which identified polarization potentials as a function of inhibitor concentration (Table 4). The inhibitor concentrations used for this testing were high levels so cracking would not be expected with polarizations less than $0.2 \mathrm{~V}$ versus Ag/AgCl. A stepwise polarization $(0.0,0.1,0.2 \mathrm{~V}$ versus $\mathrm{Ag} / \mathrm{AgCl})$ was chosen in part to verify the electrochemical results.

The inhibited conditions shifted the open-circuit potentials to more electropositive or passive values as compared to the second series data, ranging from -0.280 to $-0.360 \mathrm{~V}$ versus $\mathrm{Ag} / \mathrm{AgCl}$. The U-bends were polarized to $0.0 \mathrm{~V}$ versus $\mathrm{Ag} / \mathrm{AgCl}$ and monitored for 1.5 months. Since cracking was not observed, the polarization potential was increased to $0.1 \mathrm{~V}$ for 1 month, then $0.2 \mathrm{~V}$ for another month. Cracking was not observed on any sample. The currents followed similar trends to those observed in the first test except the steady state values tended to be a little higher $(500-1000 \mu \mathrm{A})$ for the $0.0 \mathrm{~V}$ polarization. The current levels did not change with the increase in polarization to $0.1 \mathrm{~V}$, but increased to the order of $0.01 \mathrm{~A}$ when polarization was increased to $0.2 \mathrm{~V}$. In some cases, the current levels trended lower.

The U-bends had voluminous corrosion products within the $U$ and a tenacious oxide on the exterior of the exposed U-bend. Figure 22 shows the U-bend that was exposed to $7 \mathrm{M}$ sodium nitrate with 0.3 hydroxide and $0.2 \mathrm{M}$ nitrite. Fewer corrosion products were found on those exposed to solutions containing $0.6 \mathrm{M}$ hydroxide.

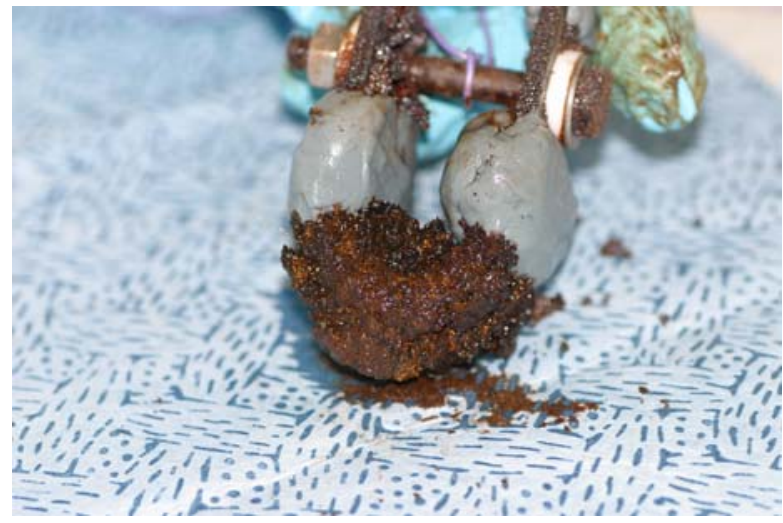

(A)

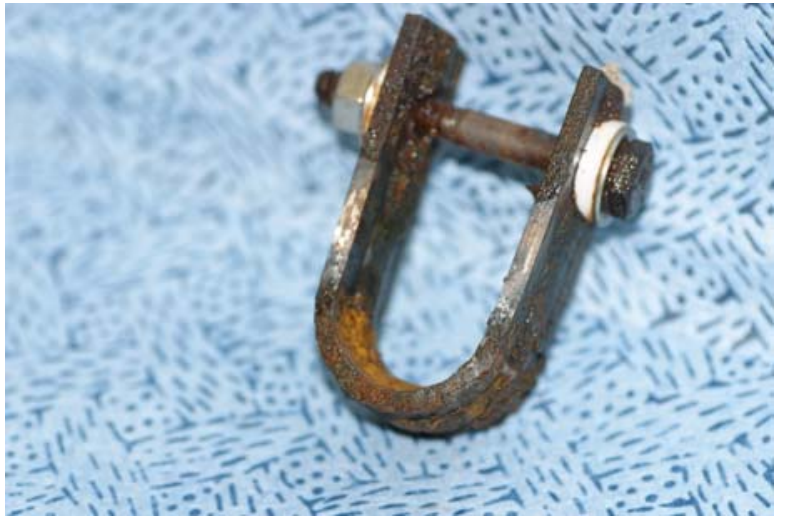

(B)

Figure 22. $\mathrm{U}$-bend exposed to $7 \mathrm{M}$ nitrate, $0.3 \mathrm{M}$ hydroxide and $0.2 \mathrm{M}$ nitrite after testing (A) and cleaned (B) of corrosion products.

\section{Conclusions}

Corrosion testing is being conducted to better characterize the necessary inhibitor concentration for high nitrate waste during salt dissolution processing. Electrochemical testing, which included cyclic polarization, linear polarization resistance and open-circuit potential measurements, was performed to identify stress corrosion cracking susceptibility, to characterize pitting resistance and to determine the general corrosion rate. Polarized U-bend tests were utilized to assess the effect of minimum inhibitor concentrations and heat treatment on SCC and to determine test parameters for future long-term U-bend testing. 
Results from CPP, LPR and OCP tests demonstrated that carbon steel formed a protective oxide film and the potential became electropositive during exposure to the waste at all inhibitor concentrations. The tenacity of this film improved as the inhibitor concentration level was increased and the temperature was decreased. This passive film increased the resistance to localized corrosion significantly. Therefore if any of these inhibitor levels are selected for storage of dissolved salt solutions, no changes to the service life estimates that were based on general corrosion are necessary.

The breakdown potential for SCC as well as the other electrochemical parameters were independent of nitrate concentration. The breakdown potential, however, was strongly affected by temperature and inhibitor concentration. These results indicate that for this nitrate concentration range a critical inhibitor level is necessary for minimizing the occurrence of SCC.

The U-bend testing clearly demonstrated that the heat treating of the samples clearly improved the SCC resistance of A537 carbon steel even at the low inhibitor concentration $(0.01 \mathrm{M}$ hydroxide and $0.01 \mathrm{M}$ nitrite). This concentration was insufficient to prevent cracking for any tested nitrate concentration (4.5-8.5 M). At a $7 \mathrm{M}$ nitrate concentration, SCC was prevented for inhibitor concentrations as low as $0.3 \mathrm{M}$ hydroxide and $0.1 \mathrm{M}$ nitrite.

\section{Acknowledgements}

The authors want to express their gratitude to Tracy Murphy for performing, organizing, and documenting the testing. The authors also acknowledge the efforts of the reviewers in the preparation of this report.

\section{References}

1. B. J. Wiersma, “An Investigation of Density Driven Salt Dissolution Techniques”, WSRCTR-96-0160, August 1996.

2. “CSTF Corrosion Control Program: Program Description Document”, WSRC-TR-200200327, Rev. 3, November 17, 2004.

3. Q. L. Nguyen, "Projected Major Chemical Compositions for Salt Dissolution Batching from Tank 41 to Tank 49 to Support Corrosion Analysis”, CBU-PIT-2005-00002, Rev. 1, February 10, 2005.

4. R. S. Ondrejcin, "Salt Removal from Waste Tanks: Nitrate-Induced Stress-Corrosion Cracking”, DPST-80-419, June 30, 1980.

5. B. J. Wiersma, "Task Plan for the Determination of Corrosion Inhibitor Criteria for Type III/IIIA Tanks During Salt Dissolution Operations”, SRNL-MTS-2005-50019, August 10, 2005.

6. Certified Material Test Report for ASTM A633 01 Gr C, American Alloy Steel, 2005.

7. R. S. Ondrejcin, "Prediction of Stress Corrosion of Carbon Steel by Nuclear Process Liquid Waste”, DP-1478, August 1978.

8. G. S. Frankel and Z. Xia, "Localized Corrosion and Stress Corrosion Cracking Resistance of Friction Stir Welded Aluminum Alloy 5454”, Corrosion, Vol. 55, No. 2, pp. 139-150, February, 1999. 
9. "Expert Panel Workshop for Hanford Site Double-Shell Tank Waste Chemistry Optimization”, M. Terry, Ed., RPP-RPT-22126, Rev. 0, October, 2004.

10. Uhlig's Corrosion Handbook, $2^{\text {nd }}$ Edition, Edited by R. W. Revie, The Electrochemical Society, Pennington, NJ, p. 1183-1197, 2000.

11. Uhlig's Corrosion Handbook, $2^{\text {nd }}$ Edition, Edited by R. W. Revie, The Electrochemical Society, Pennington, NJ, p. 1197-1206, 2000.

12. R. S. Ondrejcin, "Salt Removal Compositional Limits - Suggested Technical Standard for Types I, II, and IV Nuclear Waste Tanks”, DPST-83-533, July 25, 1983.

13. B. J. Wiersma, "Estimation of High Level Wste (HLW) Tank Remaining Service Life”, WSRC-TR-2005-00196, May, 2005. 